\title{
əInfluence of Submesoscale Topography on Daytime Precipitation Associated with Thermally Driven Local Circulations over a Mountainous Region
}

\author{
SeIYa Nishizawa, ${ }^{\mathrm{a}}$ Tsuyoshi Yamaura,,${ }^{\mathrm{a}, \mathrm{b}}$ AND Yoshiyuki KaJIKawa ${ }^{\mathrm{a}, \mathrm{b}}$ \\ ${ }^{\mathrm{a}}$ RIKEN Center for Computational Science, Kobe, Japan \\ ${ }^{\mathrm{b}}$ Research Center for Urban Safety and Security, Kobe University, Kobe, Japan
}

(Manuscript received 6 November 2020, in final form 26 April 2021)

\begin{abstract}
In this study, the effect of submesoscale topography (i.e., topographical features smaller than a few kilometers in size) on precipitation associated with thermally driven local circulations over a mountainous region is examined in the absence of synoptic-scale precipitation systems through a 100-m-mesh large-eddy simulation experiment. The observed effect of topography on precipitation is different than that identified in previous studies; submesoscale topography is observed to induce a weakening effect on precipitation in this study, while previous studies have suggested that submesoscale topography enhances precipitation. This discrepancy between studies is owing to differences in the scale of the topography and the precipitation-inducing system under consideration. Previous studies have focused on precipitation associated with synoptic-scale systems, where mechanical orographic forcing is dominant. The mechanism of the topographic effect where thermal orographic forcing is dominant was clarified in this study. Under thermally driven local circulation, the convergence of upslope flow near large-scale mountain ridges is one of the main causes of precipitation. Submesoscale topographic features promote the detachment of upslope flow from the mountain surface and vertical mixing in the boundary layer. This detachment and mixing result in a weakening of convergence and updraft and reduction of equivalent potential temperature around the ridge that explains the observed weakening effect on precipitation. Cold pools formed by evaporation of rainfall associated with upslope flow enhance the weakening effect. These results confirm the importance of submesoscale topography in orographic precipitation.
\end{abstract}

KEYWORDS: Orographic effects; Precipitation; Valley/mountain flows

\section{Introduction}

Topography has a notable influence on precipitation owing to a number of different mechanisms (e.g., Banta 1984; Frei and Schär 1998; Smith et al. 2005; Daly et al. 2008; Smith et al. 2009; Houze 2012). There are two main types of topographic forcing: mechanical and thermal (e.g., Kirshbaum et al. 2018). The dominant mechanism depends on environmental conditions such as the background wind speed, static stability, and mountain height and shape (e.g., Smith 1989). Mechanical forcing involves large-scale upslope ascent over a topographic slope and horizontal convergence by dynamic changes in the flow direction. Thermal changes caused by daytime insolation and nocturnal radiative cooling produce hydrostatic pressure gradients that induce ascending or descending winds on mountain surfaces (e.g., Egger 1990). Such flows cause convergence and orographic precipitation.

Topographic effects are dependent on the scale of topography (e.g., Kimura and Kuwagata 1995; Kuwagata et al. 2001). To date, most research on the influence of topography on precipitation has only considered large topographical features (larger than a few kilometers); most precipitation-inducing phenomena are larger than a few kilometers in size. However, it has been suggested that there may be a relation between

¿ Denotes content that is immediately available upon publication as open access.

Corresponding author: Seiya Nishizawa, s-nishizawa@riken.jp precipitation and small-scale (submesoscale) topography (smaller than a few kilometers). Nevertheless, such a relation would be far more complex than that between precipitation and larger-scale topography (e.g., Roe 2005). Submesoscale topography likely has a direct effect on submesoscale motions such as atmospheric turbulence. In the planetary boundary layer, turbulence plays an important role in precipitation processes through upward heat and moisture transfer, as well as in triggering moist convection by lifting air to the level of free convection (e.g., Emori 1998). Therefore, submesoscale topography may affect precipitation by impacting atmospheric turbulence, particularly by altering the position and timing of convection initiation.

Despite the presumed influence of submesoscale topography on precipitation, it is not well understood. One reason for this is the small scale of the phenomena that directly interact with submesoscale topography, such as local circulation and boundary layer turbulence caused by topography. To resolve them, simulations or observations with a high spatiotemporal resolution are required. Recently, several studies using largeeddy simulation (LES) with a mesh scale of order $100 \mathrm{~m}$ have been initiated to examine thermally driven orographic dry convection (Serafin and Zardi 2010; Schmidli 2013; Wagner et al. 2014, 2015) and moist convection (Kirshbaum 2011; Kirshbaum and Grant 2012; Panosetti et al. 2016). Although these simulations resolved submesoscale phenomena, these studies focused on larger-scale topography and submesoscale topographic features were not included in their simulations. Another reason for the lack of studies on the influence of submesoscale topography is the variety of topography and 


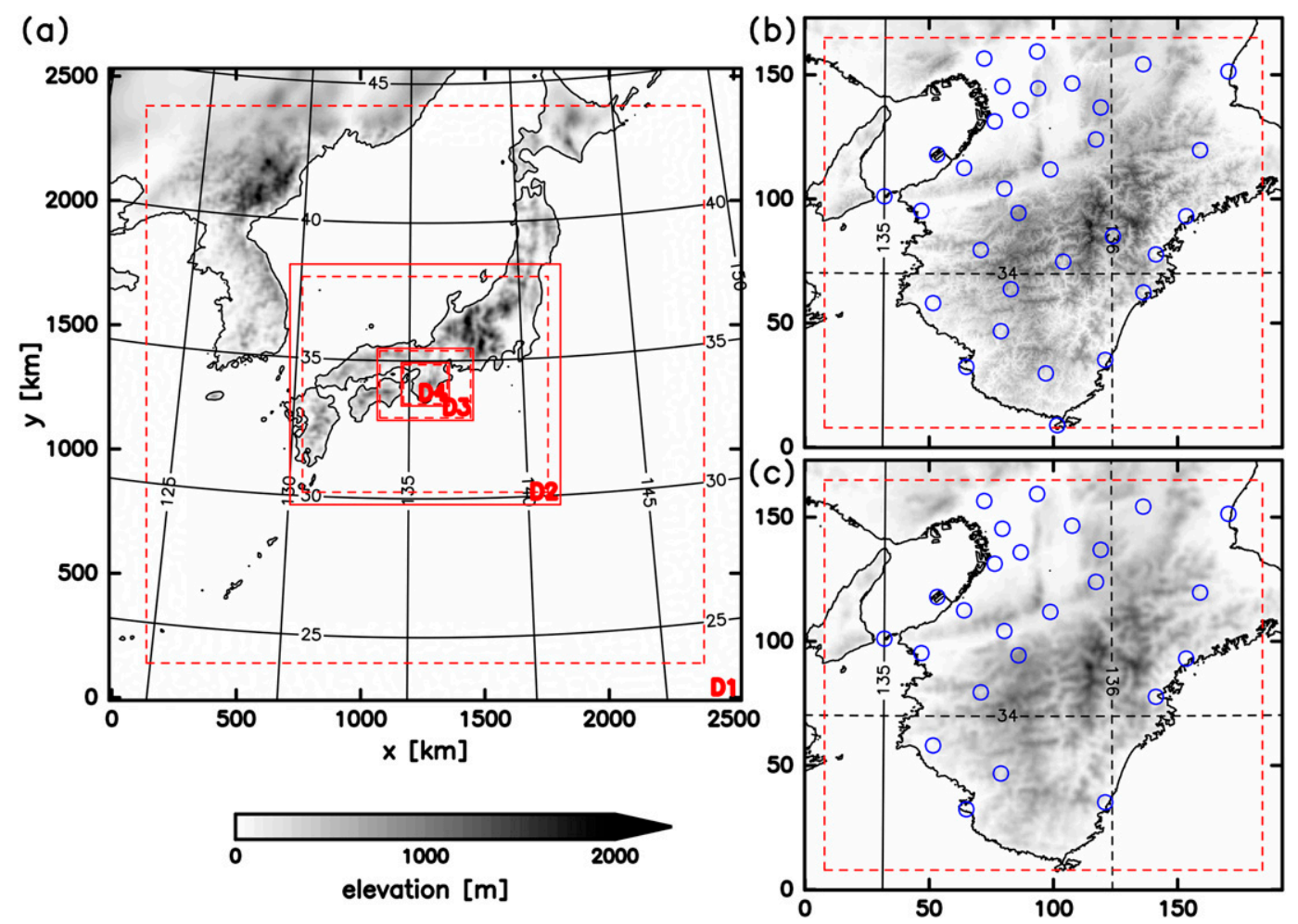

FIG. 1. (a) Topographic elevation (m) and simulation area for domains I, II, III, and IV, represented by D1, D2, D3, and D4, respectively, and elevation in domain IV in (b) TOPO100m and (c) TOPO1km. Dashed red lines show the region for lateral nudging. The blue circles indicate the locations of the ground observation stations used in the analysis. The unit of the axes is $\mathrm{km}$.

local circulation in the real world. Previous LES studies have examined the effect of idealized topography. However, complex topography with multiscale components must be considered to understand the effect of realistic topography. Small-scale components embedded in large-scale topography may alter the effect of large-scale topography. In addition, local circulation drastically changes the properties of the local atmosphere from those of the surrounding flow (Kalthoff et al. 2011), and there is great variation in local circulation, even with the same topography. Therefore, to understand the effects of submesoscale topography, statistical treatment is necessary, for which a large number of samples are needed.

A few studies have investigated the influence of submesoscale topography on precipitation with realistic topography. Numerical simulations using a terrain height dataset with subkilometer resolution enhanced the simulated precipitation of a coastal front associated with a typhoon (Oizumi et al. 2018) and a stationary linear-shaped convective system under the baiu front ${ }^{1}$ (Takemi 2018). Under these circumstances, submesoscale topography is thought to enhance the mechanical effects of largerscale topography on precipitation. For instance, Takemi (2018)

\footnotetext{
${ }^{1}$ The baiu front is a nearly stationary lower-tropospheric baroclinic zone between east China and southern Japan and occurs from late spring to early summer.
}

suggested that small-scale topography strengthens near-surface convergence, leading to greater precipitation. In both studies, however, the investigated precipitation system was of a synoptic scale, and mechanical forcing was the dominant form of topographic forcing by large-scale features.

Submesoscale topography may have a different effect on precipitation when the dominant topographic forcing by largescale features is thermal forcing. Local circulation with upslope flow driven via daytime insolation of a mountain slope induces convection initiation around the mountain ridge. As thermally driven circulation and synoptic-scale systems differ considerably in terms of the mechanism and horizontal scale, submesoscale topography could have a different influence on precipitation associated with local circulation than on precipitation associated with synoptic-scale systems. Moreover, local circulation itself is more directly linked to topography than synoptic-scale circulation as it is driven by the surface heating of the mountain slope. Therefore, the influence of submesoscale topography is likely to be more significant when local circulation is the dominant process.

For a comprehensive understanding of the effect of topography on precipitation, understanding the individual mechanisms is crucial. In particular, broadening our understanding of the influence of submesoscale topography under thermally driven circulation is necessary. A better understanding of the influence of submesoscale topography will also help improve the reproducibility of numerical simulations. While the effects 
TABLE 1. Experimental settings for the four domains.

\begin{tabular}{lcccc}
\hline & Domain I & Domain II & Domain III & Domain IV \\
\hline Domain size $\left(\mathrm{km}^{2}\right)$ & $2520 \times 2520$ & $1080 \times 960$ & $384 \times 288$ & $192 \times 172.8$ \\
Grid spacing & $7.5 \mathrm{~km}$ & $2.5 \mathrm{~km}$ & $500 \mathrm{~m}$ & $100 \mathrm{~m}$ \\
No. of vertical layers & 48 & 60 & 80 & 136 \\
PBL turbulent model & MYNN level 2.5 model & $1 \mathrm{~km}$ & Not used \\
Topography resolution & $7.5 \mathrm{~km}$ & $2.5 \mathrm{~km}$ & $1 \mathrm{~km}(\mathrm{TOPO} 1 \mathrm{~km})$ \\
Size of lateral nudging region & $150 \mathrm{~km}$ & $50 \mathrm{~km}$ & $100 \mathrm{~m}(\mathrm{TOPO} 100 \mathrm{~m})$ \\
\hline
\end{tabular}

of subgrid-scale topography are not explicitly represented in numerical simulations, they can have a great impact on simulation reproducibility. Some attempts have been made to account for the effects of subgrid-scale topography in global atmospheric models through effective roughness length or orographic drag parameterization (e.g., Milton and Wilson 1996; Lott and Miller 1997). However, most mesoscale simulations do not consider the effects of submesoscale topography unless they are explicitly represented in the simulation with sufficiently small grid spacing, which in turn can introduce errors and uncertainties in the results.

In this paper, we aim to examine the influence of submesoscale topography on precipitation associated with thermally driven local circulations over a mountainous region. For this purpose, an LES experiment over a large domain with realistic topography was performed to resolve submesoscale variability and to collect a large number of samples with widely varying topography. To isolate the effect of submesoscale topography, a twin simulation experiment was conducted, comprising two simulation runs with identical experimental configurations but different topographic data. The first simulation used a realistic topography dataset, while the topography used in the second had no submesoscale features. Differences between the two runs were subsequently analyzed to understand the impacts on precipitation that are directly attributable to submesoscale topography. Three cases without synoptic-scale precipitation systems were selected so that we could focus on precipitation associated with local circulations.

\section{Data and methodology}

\section{a. Model and experimental settings}

The numerical simulation model used for the simulations was the Scalable Computing for Advanced Library and Environment Regional Model (SCALE-RM) (Nishizawa et al. 2015; Sato et al. 2015). The governing equations were fully compressible nonhydrostatic equations. The following parameterizations were used to represent the physical processes: cloud microphysical processes by a six-category onemoment bulk scheme (Tomita 2008), radiation transfer by a $k$-distribution scheme (Sekiguchi and Nakajima 2008), subfilter-scale turbulence by a Smagorinsky-Lilly type scheme (Brown et al. 1994; Scotti et al. 1993), surface flux by a similarity scheme (Beljaars 1995; Wilson 2001; Nishizawa and
Kitamura 2018), and land processes by a multilayer diffusion and bucket scheme. Planetary boundary layer turbulence by the MYNN level 2.5 scheme (Nakanishi and Niino 2009) was also used for the simulations in the outer domains. For nested domain calculation, a cost-effective online nesting framework (Yoshida et al. 2017) was used.

Bryan et al. (2003) suggested that a grid spacing on the order of $100 \mathrm{~m}$ should be used for appropriate turbulence representation in moist convection simulations. Therefore, we used an LES with a $100-\mathrm{m}$ mesh. One-way online nesting was used to produce four nested domains and the finest 100-m-mesh simulation was run.

The extent of each domain is shown in Fig. 1 and the corresponding settings are summarized in Table 1 . The target region of the experiment includes both the plains and mountains of the Kii Peninsula, which is the largest peninsula on the island of Honshu (the main island of Japan). This region is surrounded by ocean on three sides: west, east, and south. The highest mountain peak in the region is approximately $1900 \mathrm{~m}$, and there are many peaks and mountain ridges over $1500 \mathrm{~m}$.

To only consider effects attributable to topography and to avoid contamination by other types of surface heterogeneity, the land and surface models used uniform land-use parameters, including roughness length, albedo, and soil thermal conductivity. The typical values for deciduous broadleaf forest, which is dominant in this area, were used. The values are summarized in Table 2. All lakes and rivers were removed to eliminate extra heterogeneity.

The initial and lateral boundary data for the outermost domain were generated from the Global Analysis of the Japan Meteorological Agency (JMA; https://www.jma.go.jp/ jma/jma-eng/jma-center/nwp/nwp-top.htm). The initial surface

TABLE 2. Land-use parameters.

\begin{tabular}{lc}
\hline \multicolumn{1}{c}{ Parameter } & Value \\
\hline Maximum soil moisture & $0.5 \mathrm{~m}^{3} \mathrm{~m}^{-3}$ \\
Stomata resistance & $50 \mathrm{~s}^{-1}$ \\
Thermal conductivity & $1.0 \mathrm{~W} \mathrm{~K}^{-1} \mathrm{~m}^{-1}$ \\
Heat capacity & $2 \times 10^{6} \mathrm{~J} \mathrm{~K}^{-1} \mathrm{~m}^{-3}$ \\
Moisture diffusivity & $10^{-6} \mathrm{~m}^{2} \mathrm{~s}^{-1}$ \\
Albedo for short wave & 0.18 \\
Albedo for long wave & 0.04 \\
Roughness length for momentum & $0.5 \mathrm{~m}$ \\
Roughness length for heat and vapor & $0.068 \mathrm{~m}$ \\
\hline
\end{tabular}




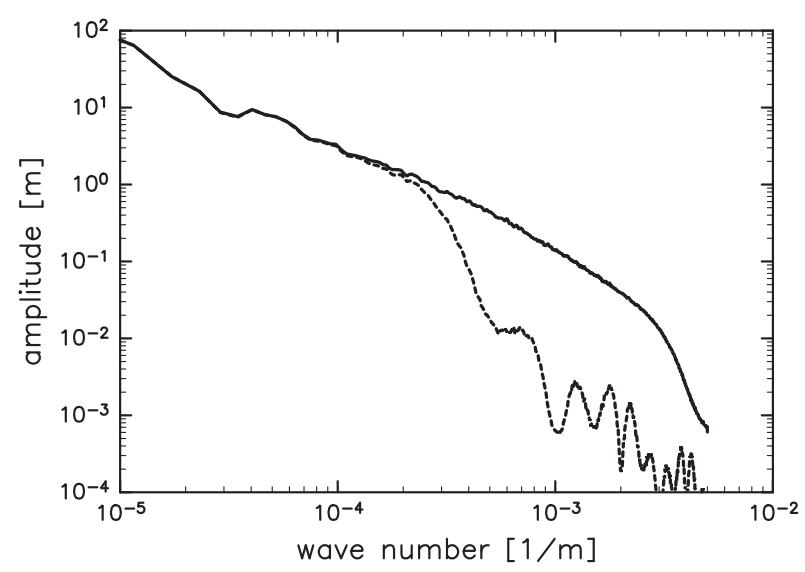

FIG. 2. Spectrum of topographic elevation for domain IV in TOPO100m (solid line) and TOPO1km (broken line).

and soil temperatures were modified considering the difference in surface elevation between the analysis and the simulation. The daily mean sea surface temperature was given externally and was generated from the Merged satellite and in situ data Global Daily Sea Surface Temperature dataset
(MGDSST; https://ds.data.jma.go.jp/gmd/goos/data/rrtdb/jmapro/mgd_sst_glb_D.html).

\section{1) TWIn SIMULATION EXPERIMENT}

To explore the effect of topography on precipitation, a twin simulation experiment was conducted. Other than topography, the experimental configuration in domain IV was identical between runs. In domains I, II, and III, the configuration including topography was identical between runs, ensuring that the lateral boundary conditions for domain IV were the same between runs.

The terrain data were generated from 50-m-mesh data based on the digital elevation model of the Geospatial Information Authority of Japan (https://www.gsi.go.jp/ENGLISH/index.html). Using real terrain data, a wide variety of topography could be considered in the experiment. During preprocessing, the elevation of each grid point was obtained via linear interpolation of the 50-m-mesh data, before a spatial numerical filter was applied to the field to remove high-wavenumber components. The filter improved the numerical stability of the simulation. For the finer-topography run (hereafter TOPO100m), the topography data of domain IV were prepared for a 100-m-mesh simulation following preprocessing (Fig. 1b). Data for the
SCALE

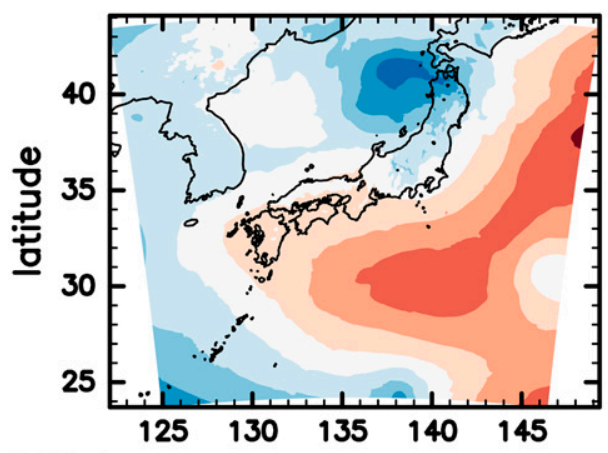

GSM

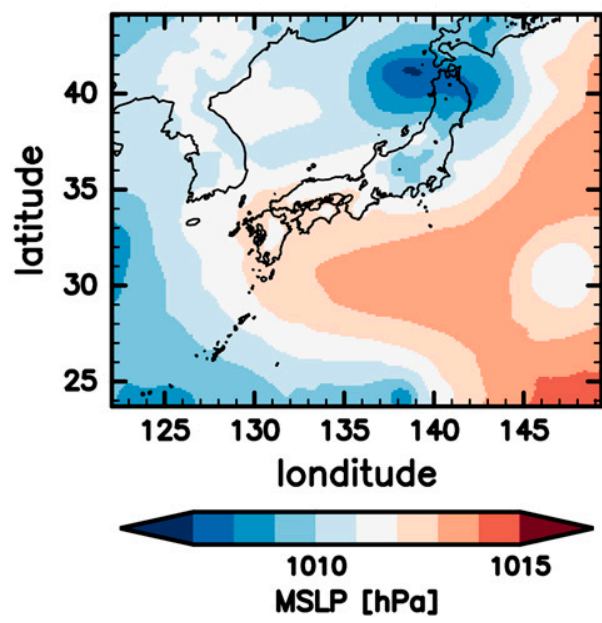

Case2

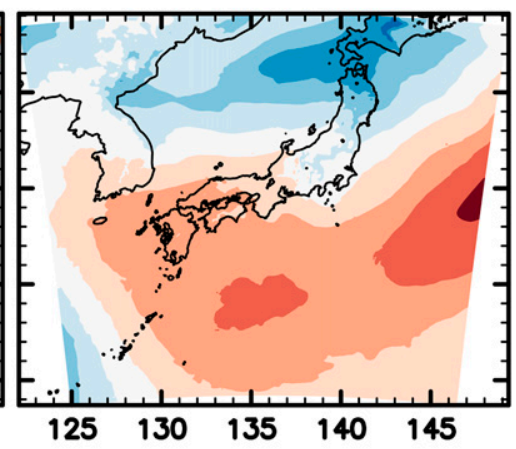

Case3

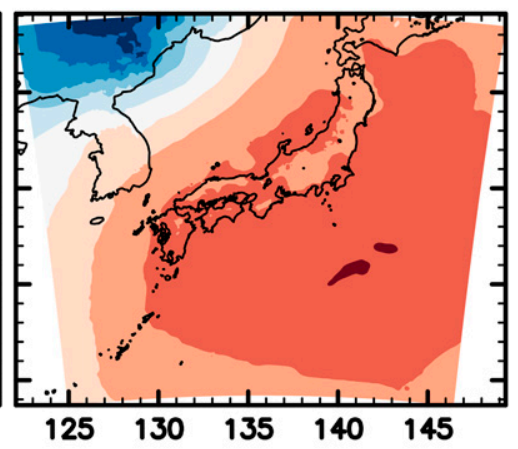

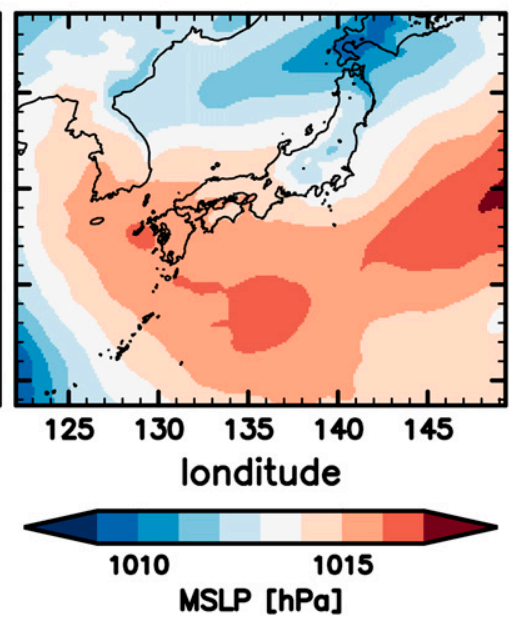

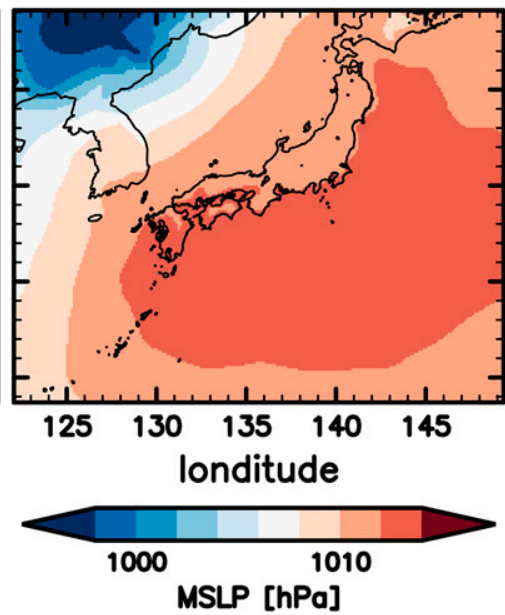

FIG. 3. Spatial distribution of the mean sea level pressure (top) simulated in domain I and (bottom) of the JMA Global Analysis at 0900 JST on (left) 14 Jul 2008, (center) 24 Jul 2010, and (right) 9 Aug 2011. 


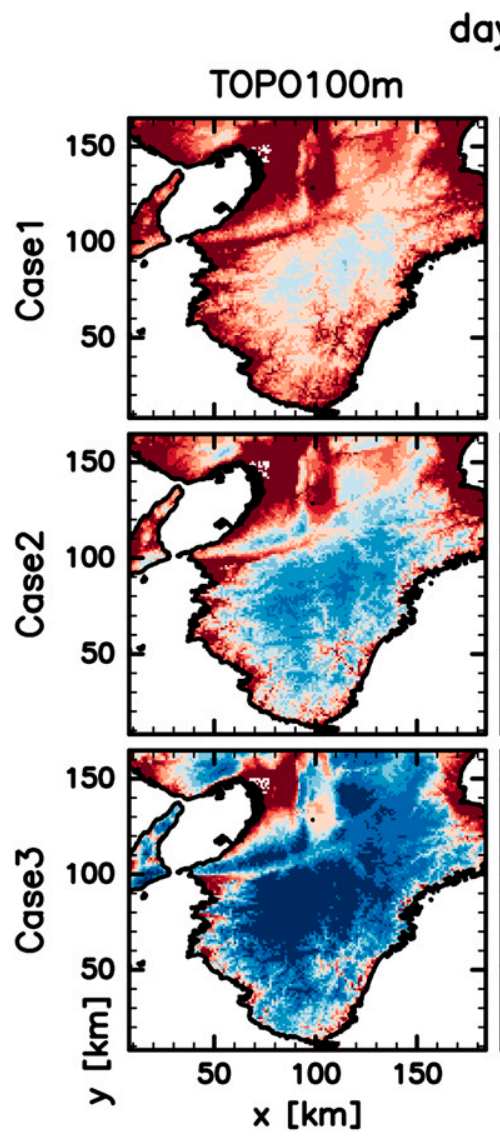

day1

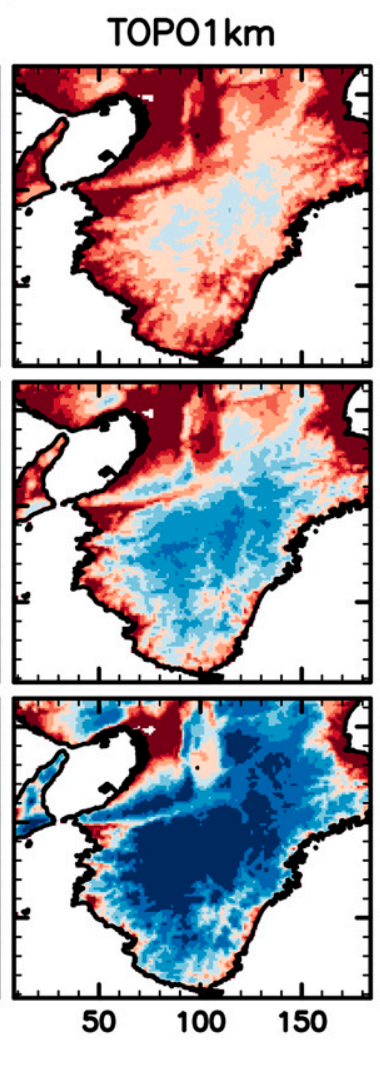

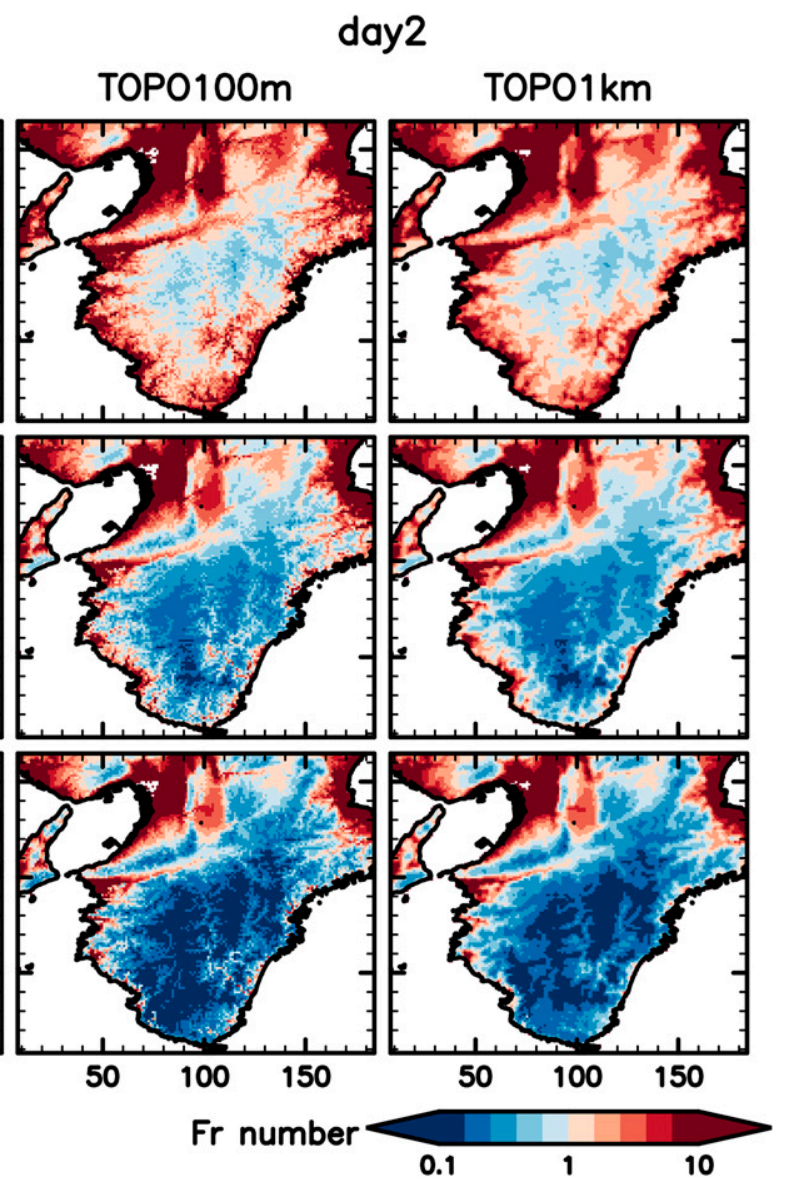

FIG. 4. Spatial distribution of the Froude number just before sunrise. The local time is 0440,0450 , and 0500 JST in cases 1 , 2, and 3 , respectively.

coarser-topography run (hereafter TOPO $1 \mathrm{~km}$ ) were prepared for a 1-km-resolution simulation and subsequently interpolated for the 100-m mesh (Fig. 1c). The filter mostly removed components smaller than $2 \mathrm{~km}$ for TOPO $1 \mathrm{~km}$ and smaller than $200 \mathrm{~m}$ for TOPO100m, as shown in Fig. 2. Components larger than approximately $3 \mathrm{~km}$ were almost identical in both runs, while submesoscale components, i.e., those smaller than a few kilometers, existed only in TOPO100m.

\section{2) TARgET CASES}

Three cases corresponding to periods with daytime precipitation without the presence of a synoptic-scale precipitation system in the target region were selected: 14-15 July 2008, 2425 July 2010, and 9-10 August 2011 (hereafter referred to as case 1 , case 2 , and case 3 , respectively). On these days, a high pressure system was present in the experimental region (Fig. 3), and temperatures rose above $300 \mathrm{~K}$ in many places. The mountain Froude number Fr (defined as $\mathrm{Fr}=V /(\mathrm{NH})$, where $V$ is the characteristic wind speed, $H$ is the mountain height, and $N$ is the Brunt-Väisälä frequency) provides a rough estimate of the dominance of thermal and mechanical forcing; the former is dominant when $\mathrm{Fr}<1$ and the latter is dominant when Fr $>1$ (e.g., Smith 1979; Hagen et al. 2011).
Figure 4 shows the Froude number immediately before sunrise on each day of each case. Here, $N$ was calculated using the vertical gradient of the virtual potential temperature between a height of 500 and $3000 \mathrm{~m}$ and $V$ was the mean velocity between these heights. Although the number was near unity in case 1 , it was mostly less than 1 over the mountainous region in all cases. This implies that thermal forcing was more dominant than mechanical forcing in these cases.

In each case, the model was run for $48 \mathrm{~h}$ from 1200 UTC [2100 Japan standard time (JST)] on 13 July 2008, 23 July 2010, and 8 August 2011. The last $39 \mathrm{~h}$ of data (i.e., 0600-2100 JST the following day) were used for analysis. The analyses were performed in domain IV except for the lateral nudging region. Several analyses were performed on daytime data, where daytime is defined as 0600-1800 JST.

\section{3) Model evaluation}

Qualitative comparisons of model-simulated data and observational data were conducted to evaluate the simulation results.

First, the synoptic-scale distribution of the mean sea level pressure was compared with the analysis data used as the initial and lateral boundary conditions. Figure 3 shows the mean sea 


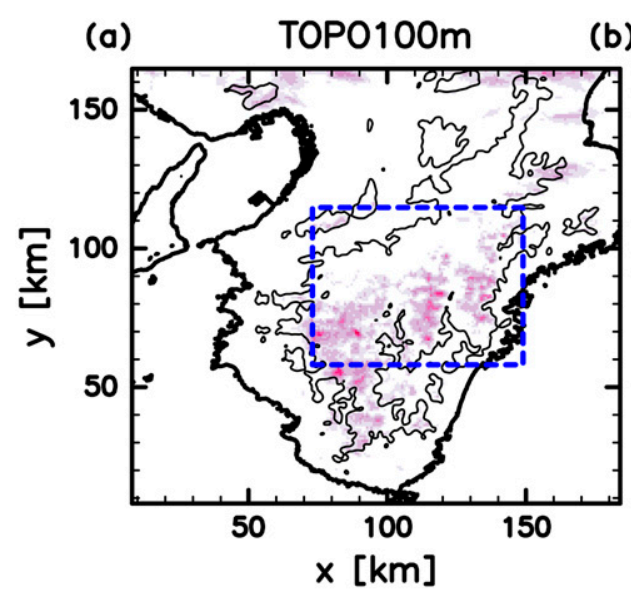

(d)

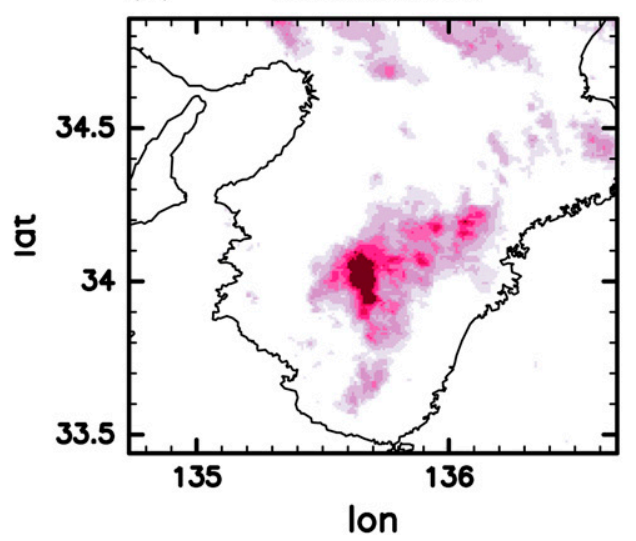

level pressure distribution of the simulation result in domain I and the analysis for the three cases. The spatial distributions show a similar pattern with a slightly different magnitude.

Second, the simulated precipitation results were compared with JMA Radar-Automated Meteorological Data Acquisition System (AMeDAS) precipitation analysis, an hourly precipitation dataset over the Japanese islands, with a spatial resolution of approximately $1 \mathrm{~km}$ based on radar and AMeDAS rain gauge network data. The spatial distribution of daytime-mean precipitation averaged over the three cases is shown in Fig. 5. Precipitation was located in a similar area. However, its magnitude was small in the simulations. The difference was the largest in case 1 .

Finally, the surface wind speed was compared with the JMA AMeDAS surface observational data. The locations of the observation stations are shown in Fig. 1. Figure 6 shows the temporal evolution of $10-\mathrm{m}$ wind speed averaged over the stations. The diurnal variations of the mean and standard deviations demonstrate good agreement in each of the cases.

These comparisons reveal that the simulation results are sufficiently realistic, although with some quantitative differences. As an idealized surface condition (i.e., homogeneous land-use parameters) was used in this experiment, the exact reproduction of observational data was not expected. The observed discrepancies notwithstanding, as we herein aimed to describe the influence of topography by comparing the
TOPO1 km

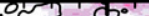

(c) TOP01 km - TOP0100m

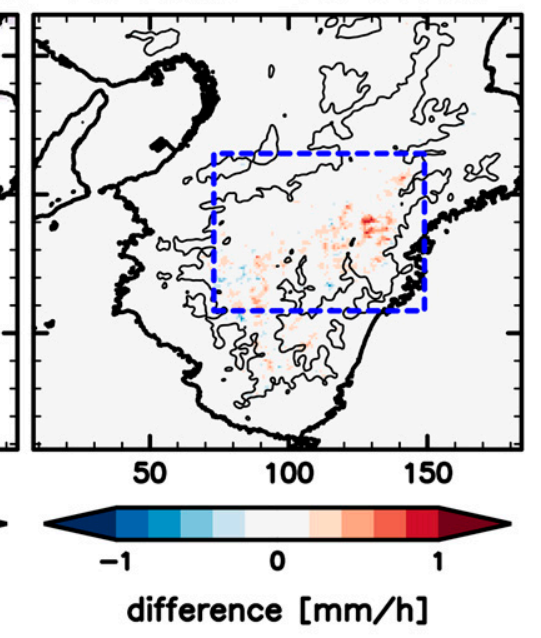

FIG. 5. Spatial distribution of (a),(b) daytime-mean precipitation averaged over the three cases in TOPO100m and TOPO1km, respectively; (c) difference between (a) and (b); and (d) daytimemean precipitation of Radar-AMeDAS observational data. The thin line represents the contour of 400-m surface elevation in TOPO $1 \mathrm{~km}$. The thick line is the coastline. The blue dashed line shows the area shown in Fig. 11.

results of twin modeling runs, the qualitative analysis was considered valid.

\section{b. Upslope flow composite}

Upslope flow on mountain slopes is one of the most important phenomena in thermally driven local circulation over mountain regions. To investigate the statistical characteristics of upslope flow, we conducted a composite analysis. To make a composite of upslope flow, typical upslope flow cases were collected.

First, ridges and valleys, defined as the local maxima and minima of the surface elevation in one direction, respectively, were detected using a ridge detection method (Lindeberg 2008) (see the appendix for details). Second, the ridge points under weak background wind conditions were extracted, in which the cross-ridge wind at the ridge was less than $1 \mathrm{~m} \mathrm{~s}^{-1}$ in the bottom layer. Third, an upslope flow region is defined for each extracted ridge point to satisfy the following conditions: (i) the region is in the normal direction of the ridge; (ii) the region does not cross a valley (i.e., the region does not extend beyond the nearest valley); (iii) the ridge is the highest point in the region (i.e., the region does not extend beyond a surface point higher than the ridge except at points within the filter length $\sigma$ from the ridge); and (iv) in the region, the along-slope wind (i.e., the wind in the direction normal to the ridge in the 

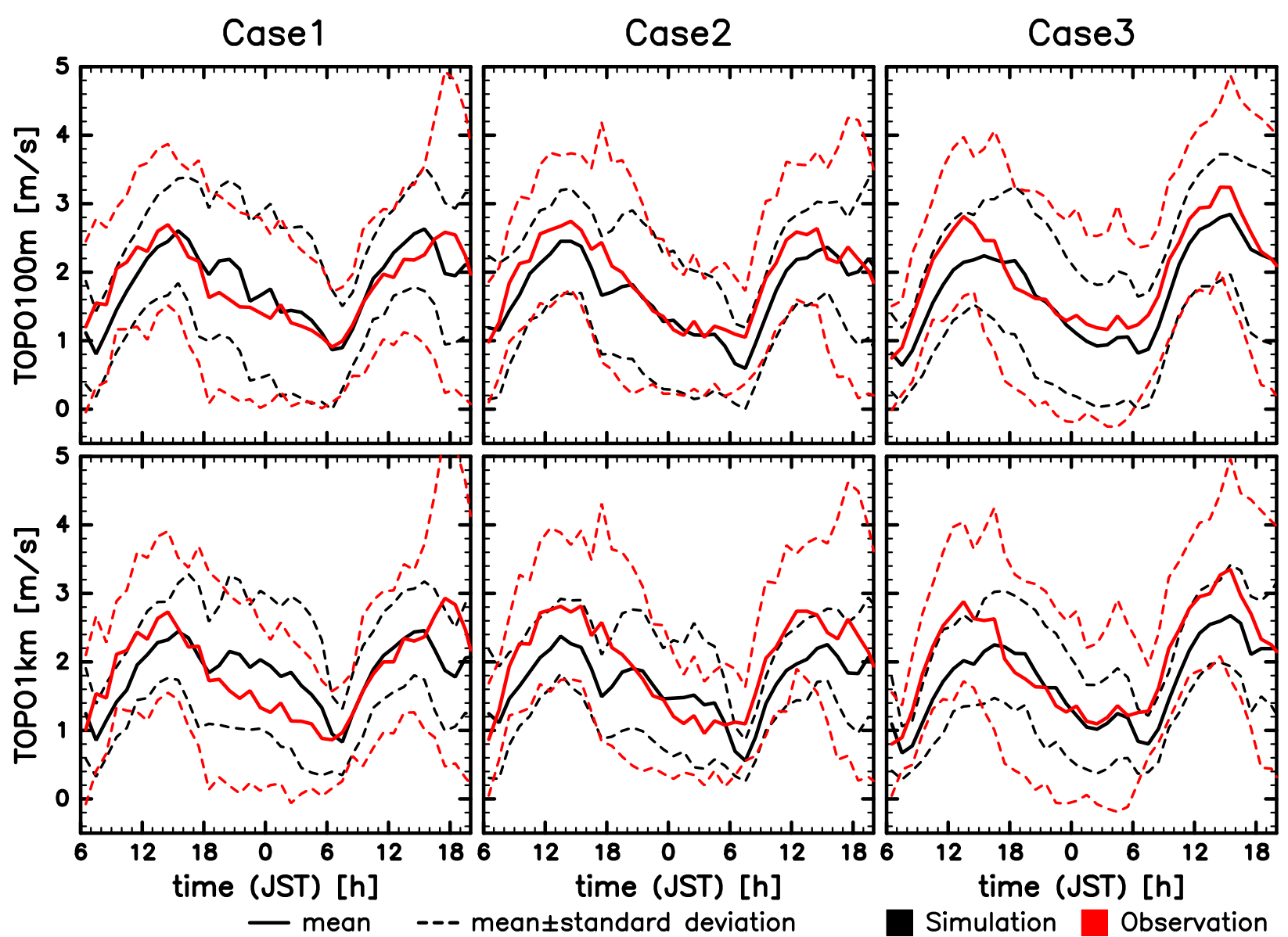

FIG. 6. Temporal evolution of 10-m absolute wind velocity averaged over the AMeDAS surface observation points shown in Fig. 1. Solid and broken lines denote the mean and range with one standard deviation, respectively. The black and red lines show the results of the simulation and AMeDAS observations, respectively.

bottom layer) is directed to the ridge, except at points within the filter length $\sigma$ from the ridge. Here, the filter length is the length used to detect the ridge (see the appendix). Fourth, along-slope winds at the bottom layer were separately averaged on both sides of the ridge in the region, and the regions in which the convergence of the upslope flow were considered strong enough (i.e., the difference in averaged wind velocity between both sides is larger than $2 \mathrm{~m} \mathrm{~s}^{-1}$ ), were collected. Finally, the variables were averaged over all collected regions to form a composite.

Figure 7 shows the temporal change in the number of collected upslope flow regions. It was found that the number drastically increased after 0800 JST, peaked at 1000-1100 JST, and then gradually decreased. Such changes are generally consistent with the change in solar heating of the slope.

The composite result can depend on the filter length $\sigma$. By varying the value, the sensitivity of the results to the value was also investigated.

\section{c. Cold pool detection}

Cold pools are an important phenomenon as they induce moist convection. To statistically investigate cold pools, a cold pool detection procedure was developed. First, cold pool fronts were detected, followed by grouping of the fronts into cold pool events.

\section{1) COLD POOL FRONT}

To detect a cold pool front, variables were temporally averaged over a certain period $T$, and three-dimensional variables were also averaged from the surface to height $H$. Cold pool fronts were defined as points where (i) the averaged potential temperature decreases by more than $\Delta T$, (ii) the averaged sensible surface heat flux is positive, (iii) the averaged liquid water pass is less than $Q_{l}$ before the cold pool front passes, (iv) the potential temperature decrease is a temporal maxima, and (v) the temperature decrease is the highest in the horizontal direction of the averaged wind.

The condition of the positive surface heat flux is to exclude temperature decrease due to surface flux. To reduce fluctuations due to turbulence, the time period $T$ was set to $30 \mathrm{~min}$, which is approximately the eddy overturning time of turbulence. The sensitivity test to $\Delta T$ and $Q_{l}$ was investigated.

Figure 8 shows an example of the temporal evolution of cold pools. Initially, cold pool fronts were detected around a 


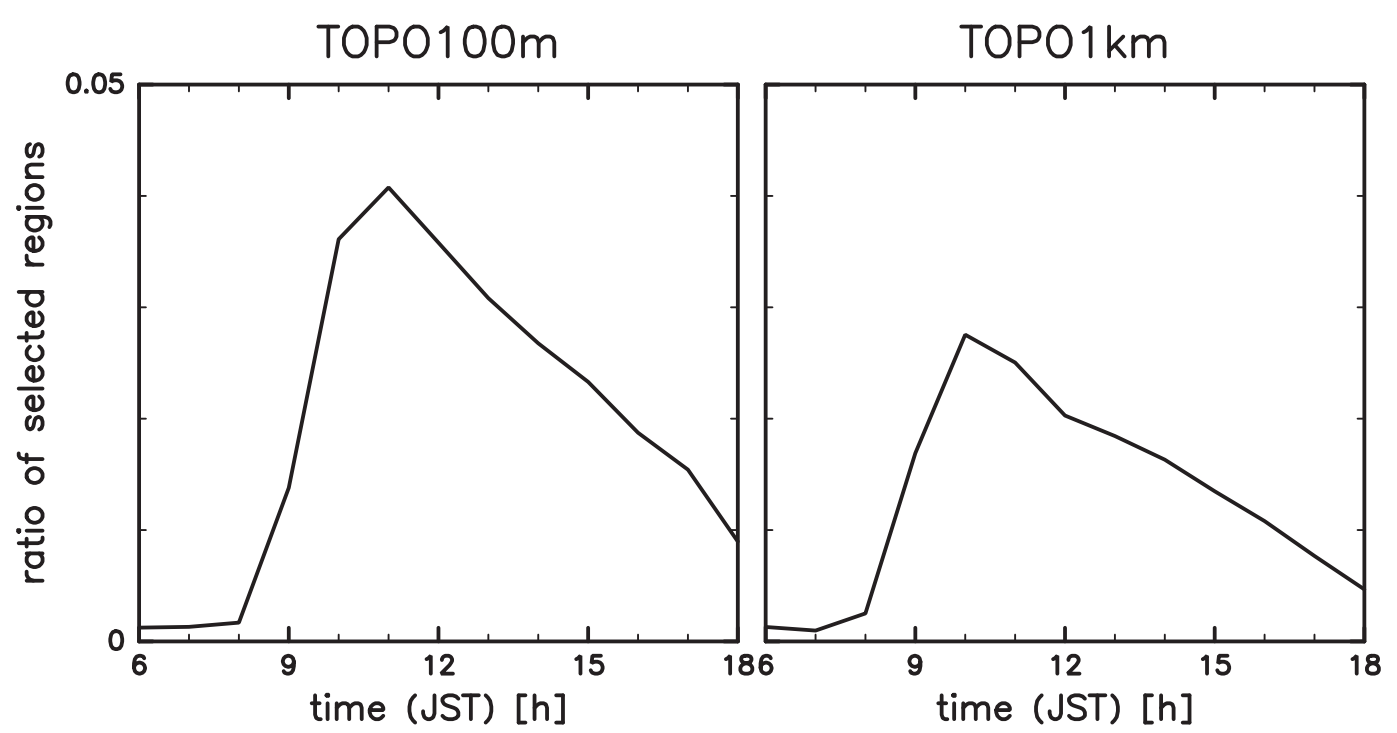

FIG. 7. Number of selected regions for upslope flow composite normalized by the total number of ridge points.

ridge at $x=80, y=75 \mathrm{~km}$; they then expanded. The movement of the detected fronts was accompanied with a large liquid water path.

\section{2) COLD POOL EVENT}

To group the cold pool fronts into cold pool events, the migration of the cold pool fronts was tracked. We defined all cold pool front points satisfying the following conditions as the same cold pool event: (i) front points at the same time step within a radius $R$ from each other and (ii) front points within radius $R$ from a point where a front point at the next time step is advected backward to the target time step.

The time when the cold pool front was first detected in a cold pool event was defined as the start time of the event, and the elapsed time from the start time was called the age of the cold pool. In addition, we excluded cold pool events originating from the ocean.

The choice of $R$ has an impact on the event grouping; a larger value tends to identify more fronts as the same event, while smaller values cause more fronts to be attributed to separate events. Different values of $R$ were used to examine the sensitivity of the result to the value.

\section{Results}

\section{a. Statistical characteristics}

Figure 5 shows the spatial distribution of daytime-mean precipitation averaged over the three cases. The amount of precipitation is larger in TOPO $1 \mathrm{~km}$ than in TOPO $100 \mathrm{~m}$. The spatial patterns of precipitation are similar in TOPO100m and TOPO1km, with most precipitation observed over mountainous areas. The rates of precipitation over the ocean are close to zero, suggesting that precipitation is linked to thermally driven convection associated with solar heating on the mountain surface.
Figure 9 shows a histogram of the 10-min daytime precipitation over land. The total precipitation is larger in TOPO1km than in TOPO100m in all three cases, suggesting that the presence of submesoscale topography reduces precipitation. This contrasts with the results of Oizumi et al. (2018) and Takemi (2018); when the mechanical effect of topography was dominant, precipitation was enhanced. The difference in total precipitation is mainly due to intense precipitation over $1 \mathrm{~mm} \mathrm{~h}^{-1}$.

The temporal evolution of mean precipitation over land shows clear variation over the course of the day (Fig. 10). Most precipitation occurs in the daytime, with a peak around 1500 JST. The difference between TOPO $100 \mathrm{~m}$ and TOPO $1 \mathrm{~km}$ is clear between morning and around $1500 \mathrm{JST}$, and at night. As the absolute magnitude of precipitation at night is small, we herein focused on daytime precipitation.

\section{b. Convection due to upslope flow}

In the morning, precipitation is clearly located over the mountainous area, with most precipitation found around the mountain ridges (Fig. 11). Figure 12 presents an example of a vertical cross section for morning wind velocity in case 3 . It clearly shows a flow climbing the slope near the surface. The upslope flow converges around the ridge, where an updraft is formed. The updraft is stronger in TOPO $1 \mathrm{~km}$ than in TOPO $100 \mathrm{~m}$. The cross section for TOPO $100 \mathrm{~m}$ shows flows in the normal direction to the land surface at several places other than the main ridge. This seems to be common, and the same observation can be made in all three cases. These flows could be forced owing to small-scale surface relief. The relation between the flow that detaches from the surface and the relief is discussed later in this subsection.

To investigate the statistical difference in updraft associated with the convergence of the upslope flow, a composite 


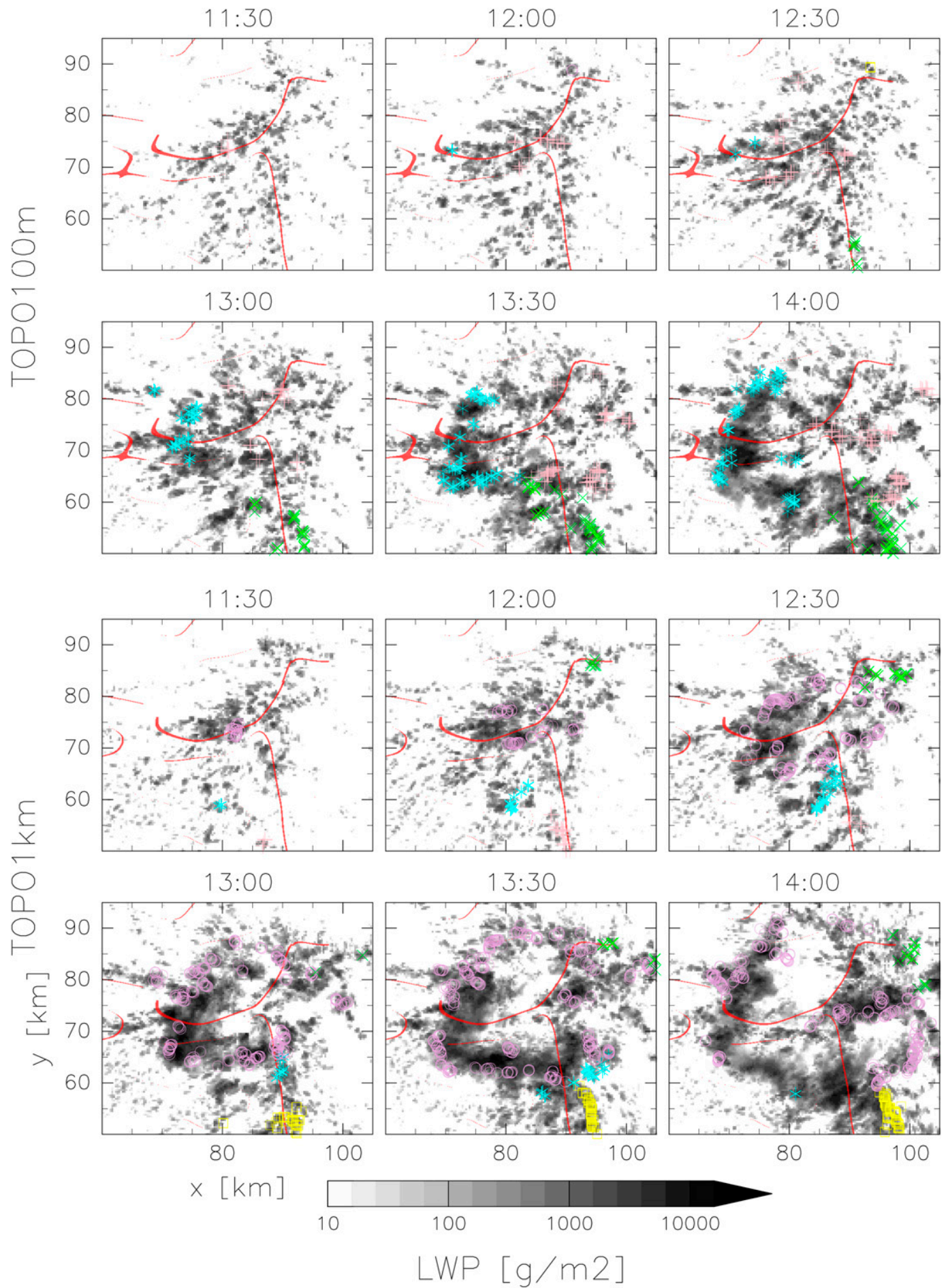

FIG. 8. Example of the temporal evolution of the liquid water path (grayscale) and the detected cold pool fronts (symbols). The same symbols represent the front points grouped as the same cold pool event. The red points are the ridge extracted by the ridge detection with $\sigma=5 \mathrm{~km}$. 

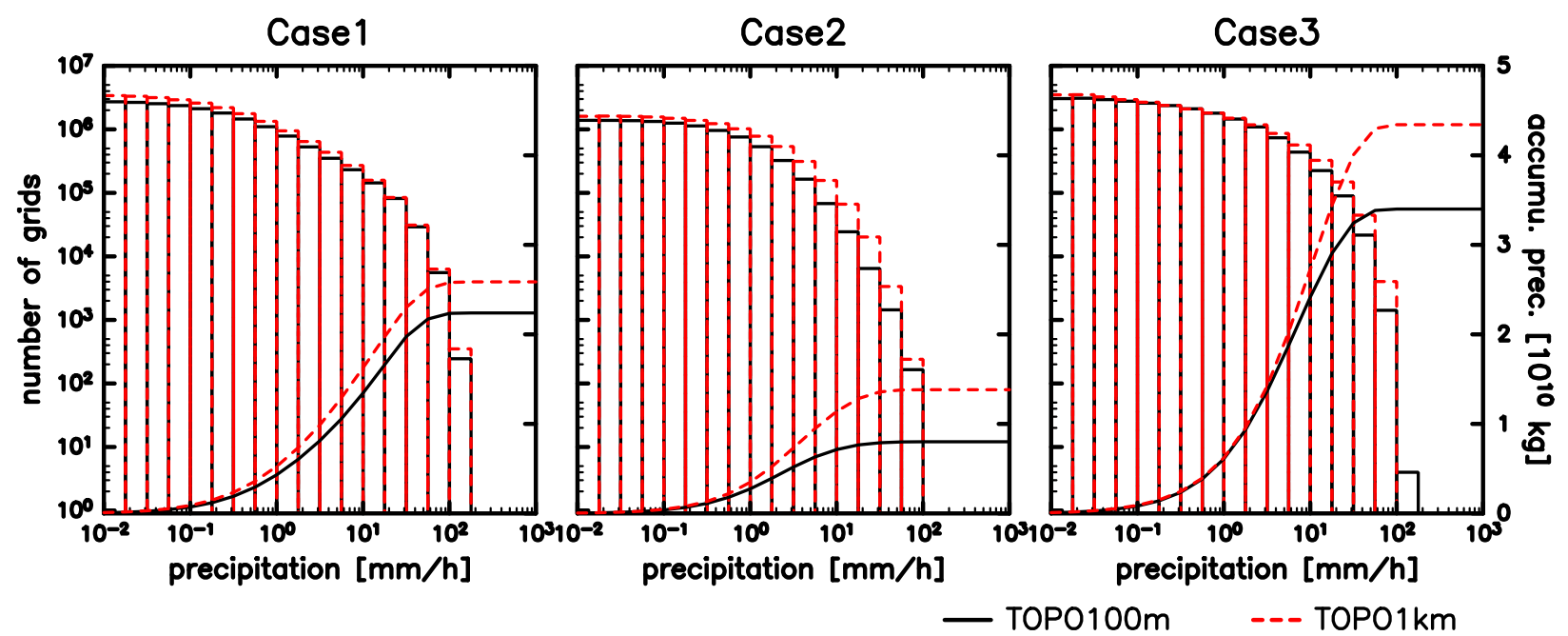

FIG. 9. Histogram (bars) and accumulated histogram (lines) of the 10-min daytime precipitation on land. The horizontal axis is in mm $\mathrm{h}^{-1}$. The results for TOPO100m are represented in black and those for TOPO1 km in red.

analysis around the ridges was performed. A composite of the cross section in the normal direction to the ridge was made, following the process described in detail in section $2 \mathrm{~b}$. To make the composite, a scale length of $1 \mathrm{~km}$ was used for ridge detection in order to extract the ridges and valleys at a larger scale than the submesoscale.
The along- and off-surface velocity, $U$ and $W$, respectively, are defined as

$$
U=\frac{\left(u+h_{x} w\right) \cos \theta+\left(v+h_{y} w\right) \sin \theta}{\sqrt{\left(h_{x} \cos \theta+h_{y} \sin \theta\right)^{2}+1}}
$$

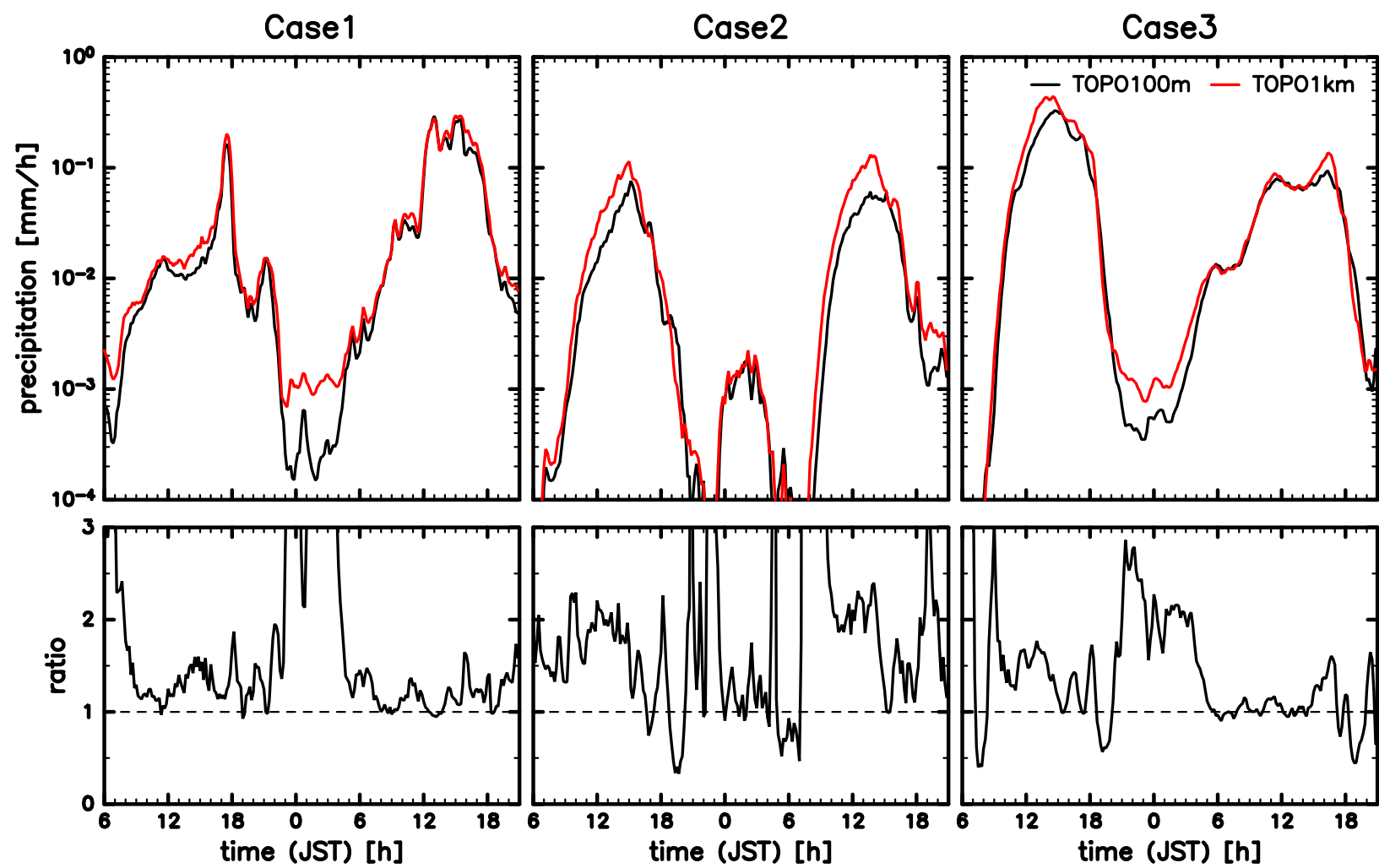

FIG. 10. Temporal evolution of (top) spatially averaged 10-min precipitation $\left(\mathrm{mm} \mathrm{h}^{-1}\right)$ on land and (bottom) ratio between those in TOPO $1 \mathrm{~km}$ and TOPO100m. The results for TOPO100m are represented in black and those for TOPO1 km in red in the top panels. The horizontal axis indicates JST. 

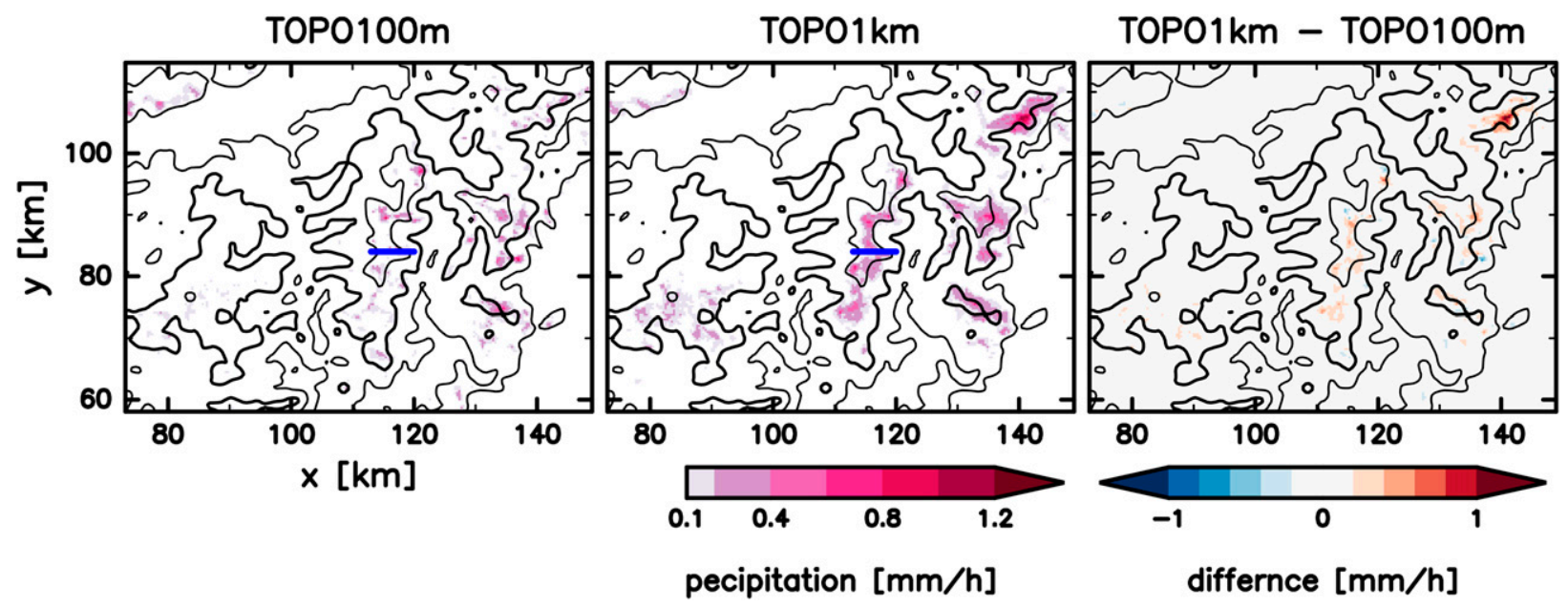

FIG. 11. As in Fig. 5, but averaged over morning (0600-1200 JST). The focus area is shown as a blue dashed line in Fig. 5. The contours represent surface elevations of 400, 800, and $1200 \mathrm{~m}$ in TOPO1km. The blue line shows the range shown in Fig. 12.

$$
W=\frac{-h_{x} u-h_{y} v+w}{\sqrt{h_{x}^{2}+h_{y}^{2}+1}},
$$

where $h$ is the surface elevation and $\theta$ is the azimuthal angle of the normal direction of the ridge line. The subscripts $x$ and $y$ indicate the derivative in the $x$ and $y$ directions, respectively. The composite of the velocity field shows that the updraft near the ridge is taller and wider in TOPO $1 \mathrm{~km}$ than in TOPO100m (Fig. 13). Corresponding to the updraft, a higher mixing ratio of hydrometeor and greater precipitation near the ridge is observed in TOPO $1 \mathrm{~km}$ than in TOPO100m.
The upslope flow transfers water vapor from the surrounding valleys and/or plains, where moisture is generally richer, to the ridge. The equivalent potential temperature $\theta_{e}$ averaged over the upslope flow is larger in TOPO $1 \mathrm{~km}$ than in TOPO100m (Fig. 14), while it shows similar values around $r \sim 5 \mathrm{~km}$, where $r$ is the distance from the ridge. The potential temperature shows similar values where $r<3 \mathrm{~km}$, indicating that the difference in $\theta_{e}$ is mainly due to the difference in water vapor. Higher values of $\theta_{e}$, i.e., more moisture, favor more active moist convection and consequently more precipitation around the ridge. Figure 15 shows the composite of convective available potential energy (CAPE); it is larger in
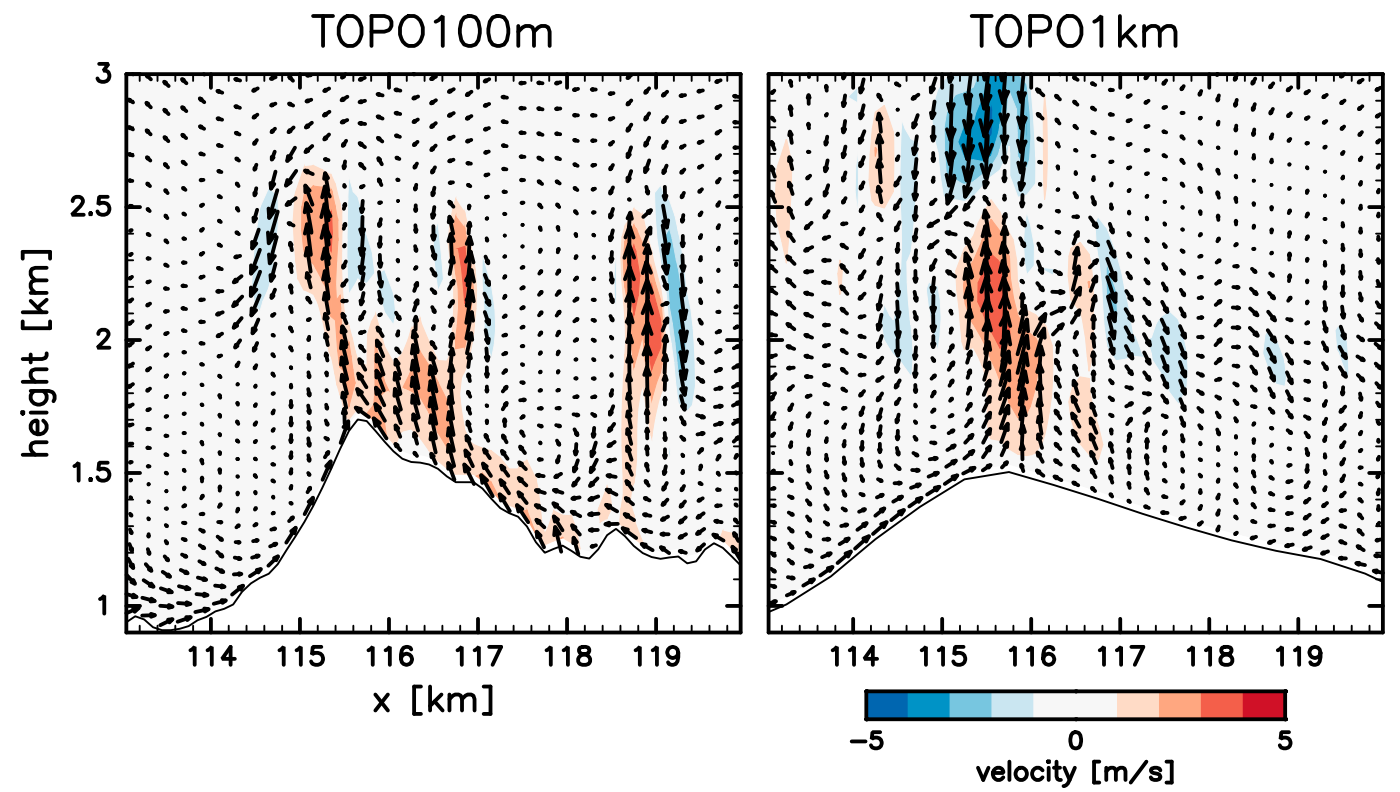

FIG. 12. Vertical cross section of projected wind (arrows) and the magnitude of its component (colors) in the direction normal to the surface at 1010 JST in case 3 at $y=84 \mathrm{~km}$. The location of this section is shown as a blue line in Fig. 11. 

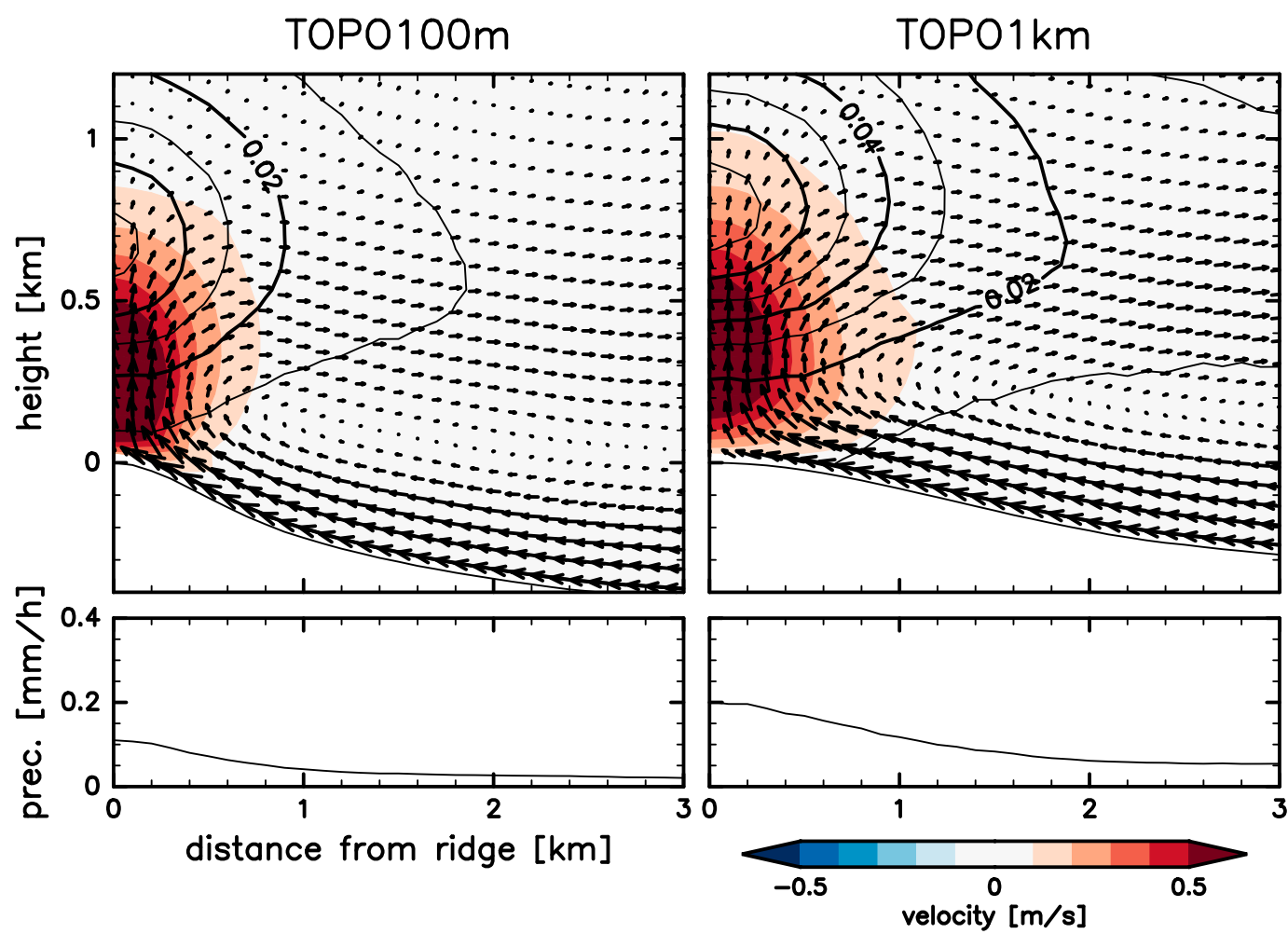

FIG. 13. Vertical cross section of the composite of the upslope flow between 0900 and 1200 JST. (top) Arrows show the flow vector $(U, W)$, colors show the magnitude of its component in the direction normal to the surface, and contours show the total hydrometeors $\left(\mathrm{g} \mathrm{kg}^{-1}\right)$. (bottom) The precipitation rate. The $x$ axis represents the distance from the ridge.

TOPO1km, corresponding to the higher $\theta_{e}$ value. The alongslope fluxes of $\theta_{e}$ and mass by the upslope flow, $f_{\theta_{e}}$ and $f_{m}$, respectively, were calculated as

$$
\begin{aligned}
& f_{\theta_{e}}=\frac{\int_{0}^{z_{\max }} \rho U \theta_{e} \cos (\theta) d z}{\int_{0}^{z_{\max }} \rho d z}, \\
& f_{m}=\frac{\int_{0}^{z_{\max }} \rho U \cos (\theta) d z}{\int_{0}^{z_{\max }} \rho d z},
\end{aligned}
$$

where $\tan \theta=d h / d r$, and $z_{\max }=400 \mathrm{~m}$. The flux of $\theta_{e}$ and momentum toward the ridge is larger in TOPO $1 \mathrm{~km}$, i.e., large negative values, than in TOPO $100 \mathrm{~m}$, which is consistent with the higher $\theta_{e}$ (Fig. 14). The flux tends to decrease with decreasing distance, indicating that the flux is converging in the slope direction. The convergence is especially large around $r \sim$ $3-4 \mathrm{~km}$ in TOPO100m. In general, updrafts reduce the local $\theta_{e}$ and momentum by ventilating air with high $\theta_{e}$ and large momentum into the upper atmosphere. Many detachments observed at places other than the ridge due to the small-scale relief in TOPO $100 \mathrm{~m}$ generate more vertical motions than in TOPO $1 \mathrm{~km}$, which is consistent with the larger convergence and smaller flux. Turbulence also reduces the flux by mixing with upper air. Figure 16 shows the mean and standard deviations of $U, W$, and $\partial U / \partial t$ averaged up to a height of $300 \mathrm{~m}$. The standard deviation of these quantities is larger in TOPO100m than in TOPO1km, while their mean values show negligible difference. The larger standard deviations of velocities support the larger variety of the direction of the surface flow and/or larger turbulent activity in TOPO100m than in TOPO1km. For surface flow detachment, it is important that the surface is not streamlined (e.g., Hoerner 1965), and detachments are more likely to occur with larger surface curvature, which generally characterizes small-scale topographic features. An adverse pressure gradient, which is a pressure change opposing the fluid motion, is necessary for the detachment (e.g., Pritchard and Leylegian 2011). The larger standard deviation of the pressure gradient force suggests that adverse pressure gradients occur more frequently in TOPO $100 \mathrm{~m}$. In summary, small-scale relief induces the detachment of upslope flows and vertical mixing via turbulent activity, reduces the convergence of mass and moisture fluxes to large-scale ridges, and alters the conditions for moist convection.

We conducted sensitivity tests in the upslope flow composite analysis with a different length scale of ridge detection of $2 \mathrm{~km}$. The results of the sensitivity tests confirmed that our conclusions are not qualitatively dependent on the value. Furthermore, all analyses were individually performed for each case (i.e., case 1 , case 2, and case 3 ), as they 

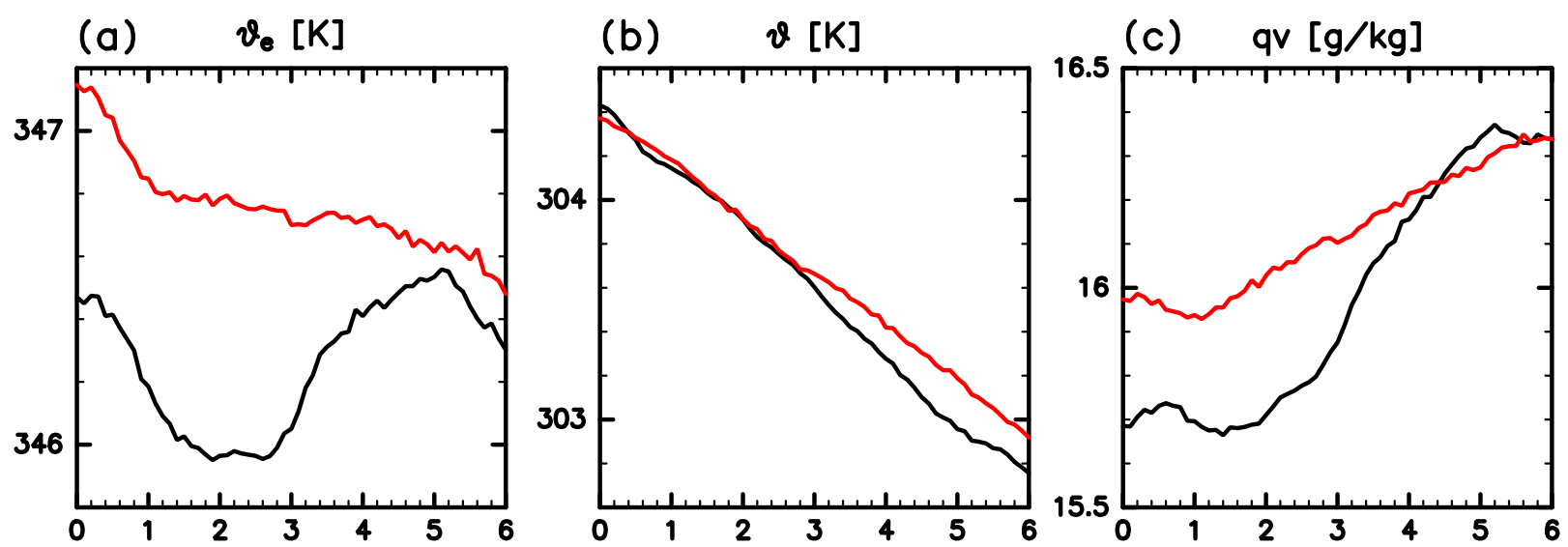

(d) $v_{e}$ flux $[\mathrm{Km} / \mathrm{s}]$

(e) mass flux $[\mathrm{m} / \mathrm{s}]$
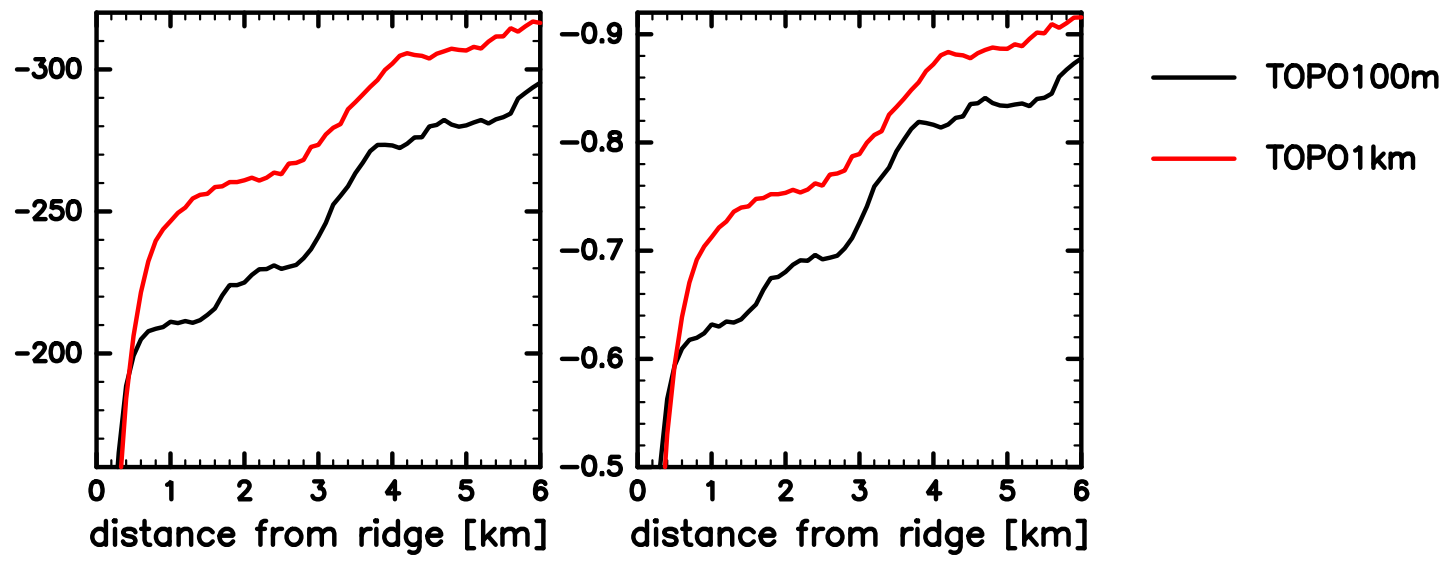

FIG. 14. Dependency of the composite of (a) equivalent potential temperature, (b) potential temperature, (c) specific humidity, (d) equivalent potential temperature flux, and (e) mass flux averaged from the surface to 400-m height on the distance from ridge. The results for TOPO100m are represented in black and those for TOPO1km are in red.

were with all three cases considered collectively as conducted above. The same qualitative results were obtained when each case was separately analyzed. These corroborate the robustness of the results obtained.

To substantiate the differences in vertical motion, an analysis of upward plumes was conducted. A plume is defined as a cluster of upward flow larger than a certain threshold value; any adjacent grids that have a vertical velocity larger than the threshold value are grouped together as the same plume. Note that various stages of a plume's life are included as they are detected instantaneously. A strong plume is defined with as one having a threshold vertical velocity of $5 \mathrm{~m} \mathrm{~s}^{-1}$; a weak plume is defined as having a threshold vertical velocity of $2 \mathrm{~m} \mathrm{~s}^{-1}$. Here, the definition of weak plumes excludes plumes with a maximum vertical velocity $>5 \mathrm{~m} \mathrm{~s}^{-1}$. Figure 17 shows the characteristics of the plumes. The strong and weak plumes are most abundant around 1400 and 1200 JST, respectively (Figs. 17a,g). The number of strong plumes is larger in TOPO1km than in TOPO100m, while the number of weak plumes is much larger in TOPO100m. The daytime-mean number of weak plumes with a top height of $<2 \mathrm{~km}$ is much larger in TOPO100m than in TOPO1km (Fig. 17i). However, the number of strong plumes with top heights $>2 \mathrm{~km}$ is larger in TOPO1km (Fig. 17c). The mean plume-top height is consistently higher in TOPO $1 \mathrm{~km}$ than in TOPO $100 \mathrm{~m}$ for both the weak and strong plumes during the daytime (Figs. 17b,h). This indicates that there are many upward plumes at lower altitudes in TOPO100m but that the majority do not reach higher altitudes. This is consistent with the many detachments and updrafts at lower altitudes discussed above. The differences in plume-top height can be attributed directly to the size of the plumes. In this study, the size of the plume is defined as the maximum horizontal size of the plume in the vertical direction. Figures $17 \mathrm{~d}$ and $17 \mathrm{j}$ show the dependencies of the daytime-mean size on the plume-top height for the strong and weak plumes, respectively. For the strong plumes, the plumes with higher top heights tend to be larger. The same trend is observed for weak plumes below $2 \mathrm{~km}$. The mean size of the strong plumes is larger in TOPO $1 \mathrm{~km}$ than in TOPO100m, and the difference increases with the height of the plume top. The mixing rate with surrounding cooler air at the plume boundary is greater for smaller plumes owing to their larger surface-to-volume ratio (e.g., Turner 1962), which in turn decreases their buoyancy and limits their capacity to gain altitude. This is a possible explanation for 


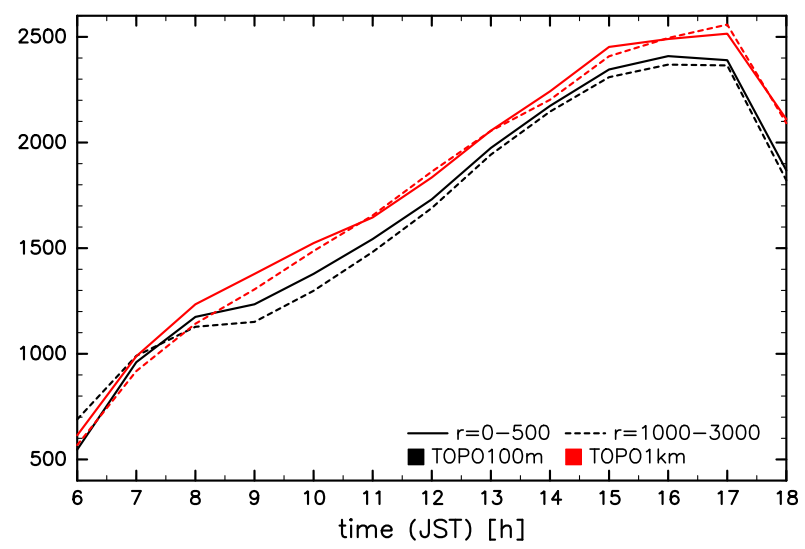

FIG. 15. Temporal evolution of the composite of CAPE. The results for TOPO100m are represented in black and those for TOPO $1 \mathrm{~km}$ are in red. The solid and broken lines show the average between $r=0-500$ and 1000-3000 m, respectively.

the presence of few strong and high plumes in TOPO $100 \mathrm{~m}$, despite the presence of many weak and low plumes.

Next, the characteristics of the moist diagnostics of the plumes were investigated. The equivalent potential temperature of a

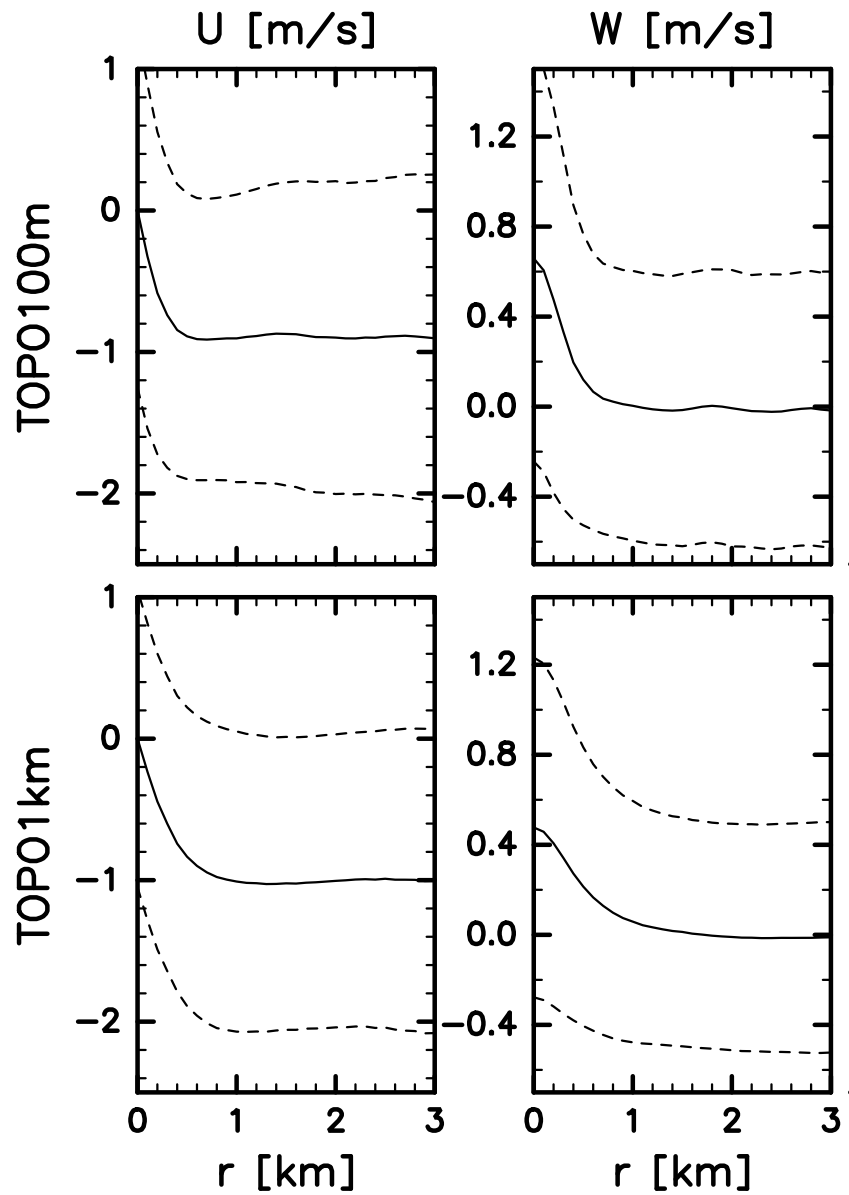

plume is defined as the maximum $\theta_{e}$ in the plume. The $\theta_{e}$ of a plume that reaches more than $2 \mathrm{~km}$ tends to be a few degrees higher in TOPO100m than in TOPO1km (Fig. 17e). This implies that the $\theta_{e}$ required for the plume to reach a certain level is higher in TOPO100m than in TOPO $1 \mathrm{~km}$. This supports the possibility of greater mixing at the plume boundary in TOPO $100 \mathrm{~m}$. Figures $17 \mathrm{f}$ and 171 show the daytime ratios of the saturated plumes that contain saturated air for the strong and weak plumes, respectively. The results show that most weak plumes are not saturated, while most strong plumes are saturated. Even though the number of plumes at a lower height is larger in TOPO100m than in TOPO1km, moist convection is less likely to occur in TOPO $100 \mathrm{~m}$ because fewer plumes reach the level of free convection. In other words, updrafts due to upslope flow convergence near large-scale ridges tend to be wider and stronger in the absence of small-scale topographic relief, resulting in more plumes becoming stronger through moist processes.

\section{c. Convection due to cold pools}

Precipitation associated with cold pools was also observed. Figures 18 and 19 show examples of the temporal evolution of the velocity and potential temperature near the surface in case 2 and case 3 , respectively. In its early stages, a large liquid
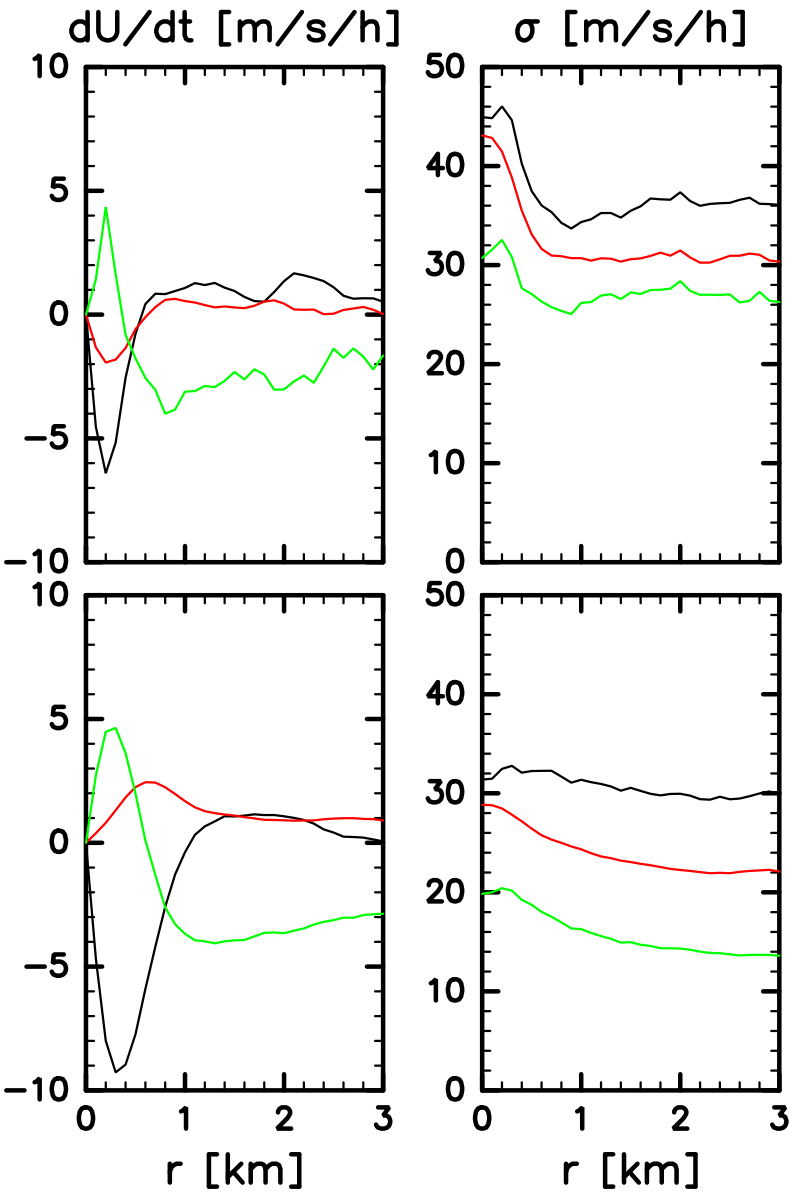

FIG. 16. Composite of (left to right) $U, W, \partial U / \partial t$, and the standard deviation of $\partial U / \partial t$, respectively. These parameters are averaged over 1000 and 1200 JST and a height of 0-300 m. The black, red, and green lines in the right two columns represent the tendency due to advection in the direction parallel to the surface, advection in the normal direction, and the pressure gradient, respectively. 

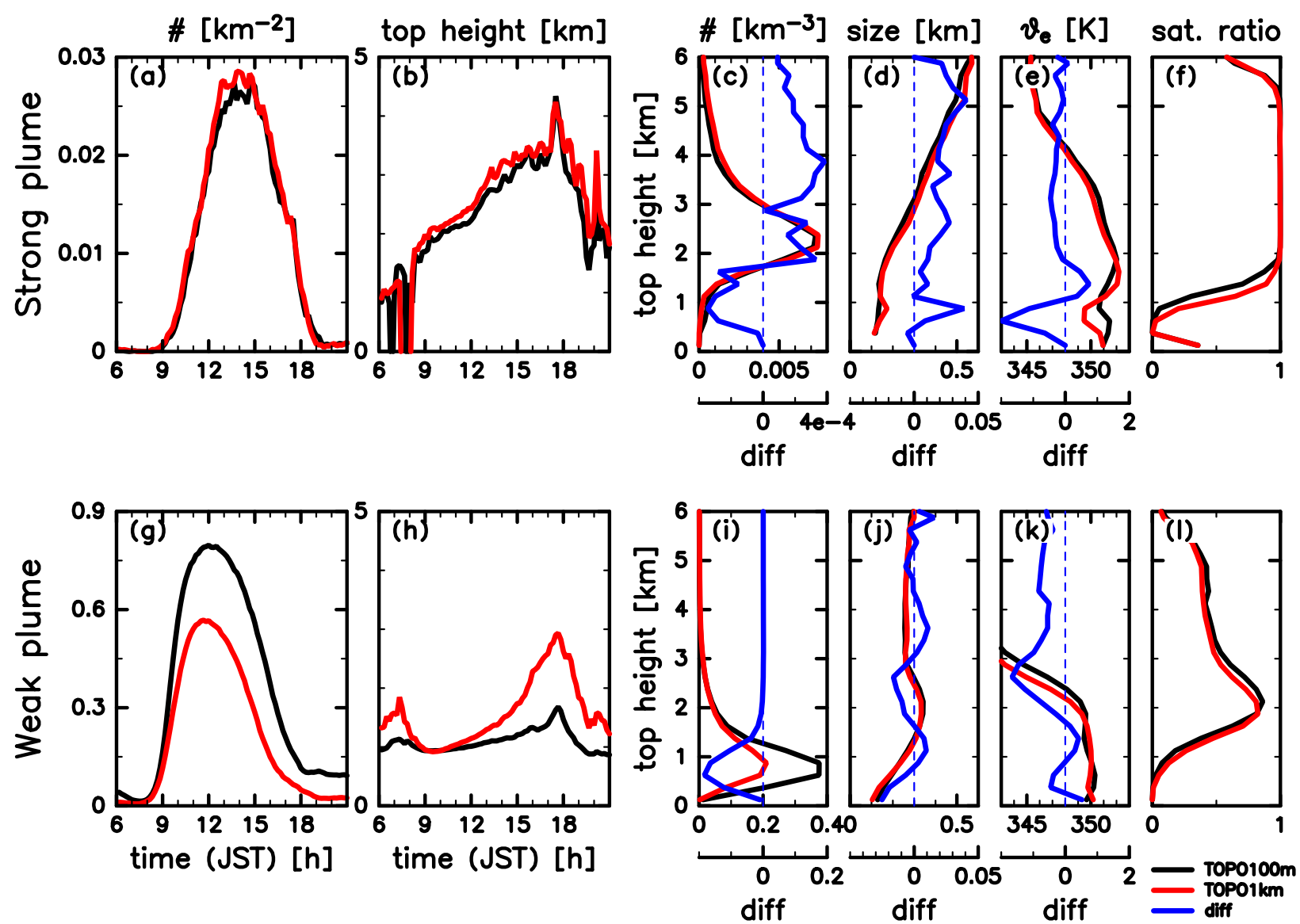

FIG. 17. Characteristics of upward plumes. Results for (top) strong and (bottom) weak plumes are shown. The temporal dependency of (a),(g) number of plumes and (b),(h) the plume-top height. The plume-top height dependency of the daytime average (c),(i) number, (d),(j) horizontal size, (e),(k) equivalent potential temperature, and (f),(1) ratio of saturated plumes. The results for TOPO100m are represented in black and those for TOPO1 km are in red. The blue lines in (c)-(e) and (i)-(k) indicate the difference between TOPO100m and TOPO1km, respectively.

water path is observed around the mountain ridge $(x=90$ $95 \mathrm{~km}$ in case 2 and $x=80-85 \mathrm{~km}$ in case 3 ). These are associated with moist convection caused by upslope flow convergence. Temperatures subsequently decrease due to the evaporation of raindrops near the surface and the cold temperature migrates eastward (westward) with eastward (westward) velocity in case 2 (case 3 ). The elevation profile shows that the cold pool travels down the mountain slope. Its downward migration is accompanied by the eastward (westward) shift of the large liquid water path in case 2 (case 3), which would indicate new convection generated by the movement of the cold pool. These characteristics are consistent with those obtained in an idealized experiment by Panosetti et al. (2016).

To statistically examine cold pools, cold pool fronts and cold pool events were detected following the procedure described in section 2c. Here, a cold pool front is defined as points where the decrease in potential temperature is locally maximum. A cold pool event is defined as a set of cold pool fronts assessed as belonging to the same event. The parameters in the detection, $H, \Delta T, Q_{l}$, and $R$ were set as $200 \mathrm{~m}, 2 \mathrm{~K} \mathrm{~h}^{-1}, 500 \mathrm{~g} \mathrm{~m}^{-2}$, and $10 \mathrm{~km}$, respectively.

Composites of the temporal evolution of potential temperature and velocity at the detected fronts in all three cases are shown in Figs. 20a and 20b, respectively. The velocity at the front corresponds approximately to the speed of the migration of the cold pool. The difference in corresponding values for TOPO100m and TOPO1km was not observed to be statistically significant, except for the initial velocity (at age $=0$ ). Composites of temporal changes in precipitation and liquid water path show that they dramatically increase when the cold pool front passes and the change in the liquid water path precedes that in the precipitation (Fig. 21). Significant differences were also not observed for these quantities. This suggests that submesoscale topography does not significantly affect the migration and evolution of cold pools in the way that it affects upslope flow, as shown in the previous subsection. On the contrary, the numbers of cold pool fronts and events are larger in TOPO $1 \mathrm{~km}$ than in TOPO100m (Figs. 20c,d). These differences existed from the beginning. The difference in the initial state was caused by differences in rainfall induced by upslope flow; more precipitation around the ridges induced by stronger upslope flow results in larger diabatic cooling due to the evaporation of precipitation near the surface. This is consistent with the significant difference in the initial velocity seen in 

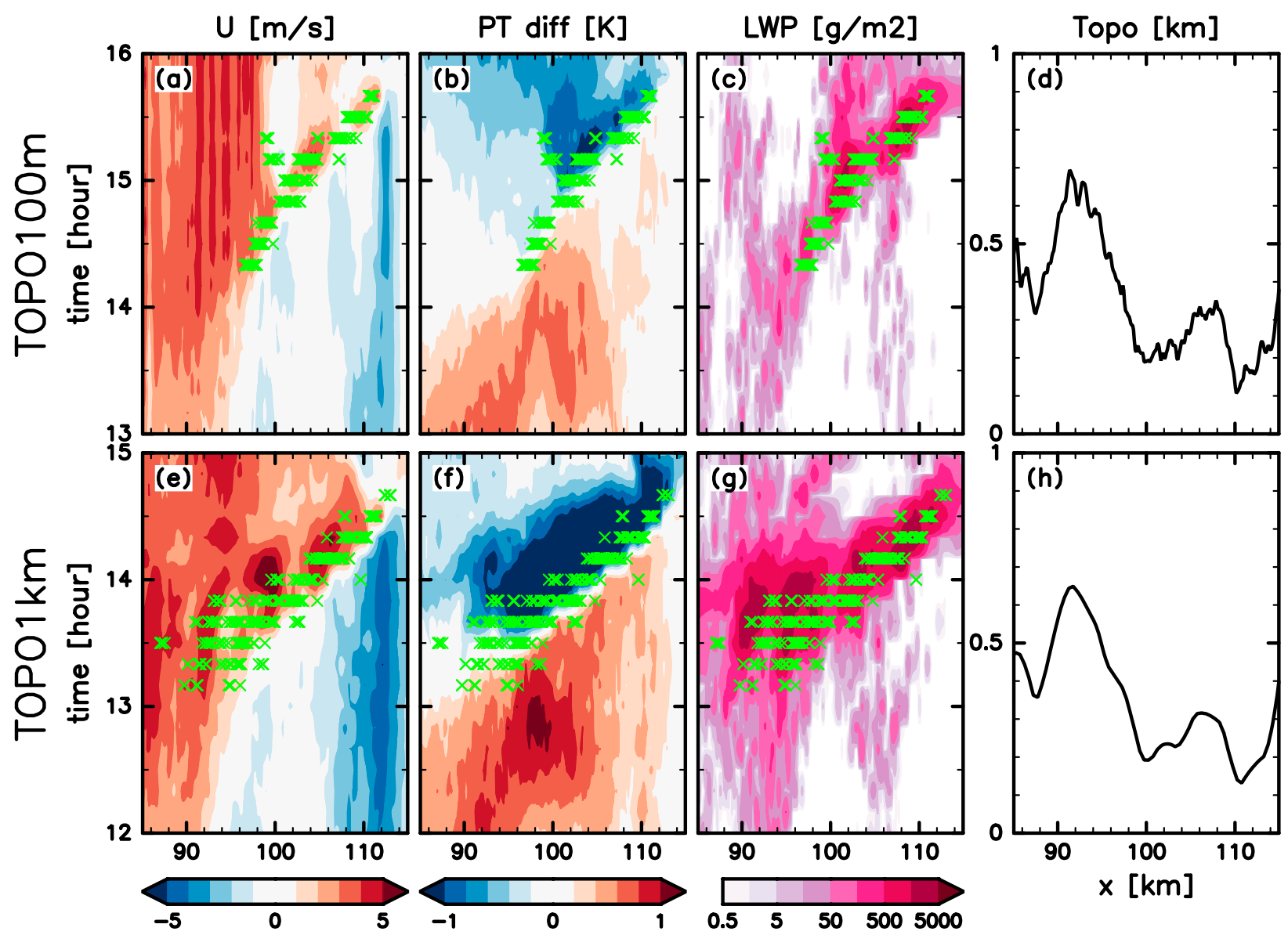

FIG. 18. Example of the temporal evolution of (a),(e) velocity, (b),(f) potential temperature anomaly, and (c),(g) liquid water path related to a cold pool event at $x=85-115 \mathrm{~km}$ averaged over $y=45-50 \mathrm{~km}$ in case 2. (d),(h) The surface elevation. Results are from (top) TOPO100m and (bottom) TOPO1km. The potential temperature anomaly is the difference from the temporal average over the shown time range. The green $\times$ symbols represent the detected cold pool fronts in the range of $y$. The $y$ axes of (a)-(c) and (e)-(g) are the hour (JST) on 25 Jul 2010.

Fig. 20b. Based on these results, it is suggested that cold pools linked to precipitation induced by the upslope flow amplify the difference in the precipitation between TOPO100m and TOPO $1 \mathrm{~km}$. In other words, cold pools enhance the weakening effect of submesoscale topography.

To explore the reason for why submesoscale topography does not have a significant impact on cold pool migration and evolution (i.e., their speed and temperature decrease), the preferred location of each cold pool front was examined. The index $F_{\text {cpf }}$ was defined to indicate whether cold pools are located near a valley or a ridge, as follows. Let $i$ indicate an individual cold pool event ( $i=1, \ldots, I)$ and let $n_{\text {total }, i}$ be the total number of cold pool front points of the event $i$, where $I$ denotes the total number of events. For all front points, determine whether the point is closer to the nearest valley or ridge; $n_{\text {valley }, i}$ is the number of cold pool front points belonging to event $i$ where the nearest valley is closer than the nearest ridge, and $n_{\text {ridge }, i}$ is the number of points where the nearest ridge is closer than the nearest valley. These numbers are then normalized by the total number and summed for all events: $N_{\bullet}=\sum_{i=1}^{I} n_{\bullet, i} / n_{\mathrm{total}, i}$, where $\bullet$ is the valley, ridge, and total. Using the total normalized number, the index is defined as

$$
F_{\text {cpf }}=\frac{N_{\text {valley }}-N_{\text {ridge }}}{N_{\text {total }}} .
$$

Alternatively, it can be written as

$$
F_{\mathrm{cpf}}=\frac{1}{I} \sum_{i=1}^{I} f_{\mathrm{cpf}, i},
$$

where $f_{\mathrm{cpf}, i}=\left(n_{\mathrm{valley}, i}-n_{\text {ridge }, i}\right) / n_{\text {total }, i}$. An index greater (smaller) than 0 indicates that cold pool fronts are more likely to be located near valleys (ridges). Following the same principle, the index $F_{\text {land }}$ can be calculated from all the land grid points instead of cold pool front points:

$$
F_{\text {land }}=\frac{n l_{\text {valley }}-n l_{\text {ridge }}}{n l_{\text {total }}} \text {, }
$$

where $n l_{\text {valley }}\left(n l_{\text {ridge }}\right)$ is the number of land grid points at which the nearest valley (ridge) is closer than the nearest ridge (valley), and $n l_{\text {total }}$ is the total number of land points. Figure 22 shows that $F_{\text {land }}$ is negative, meaning there are more ridge 

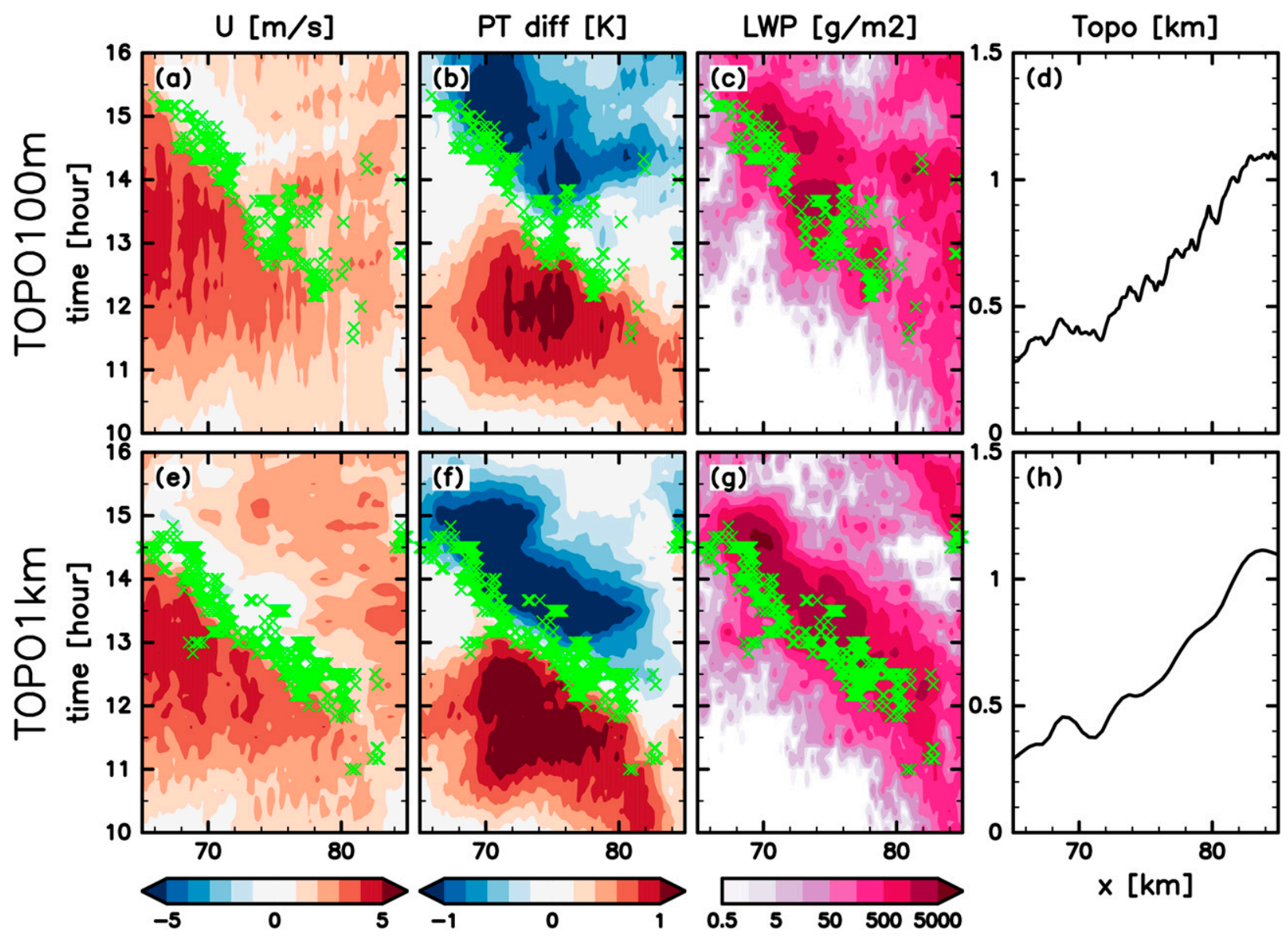

FIG. 19. As in Fig. 18, but at $x=65-85 \mathrm{~km}, y=75-80 \mathrm{~km}$ in case 3 on 9 Aug 2011.

points than valley points. This is more apparent for the larger scale length $\sigma$ of ridge detection, which is a filter length for a low-pass filter (the definition of $\sigma$ can be found in the appendix). If the cold pool front index $F_{\mathrm{cpf}}$ is greater (smaller) than the land point index $F_{\text {land }}$, then the cold pools are more likely to be located near valleys (ridges). Figure 22 shows the temporal change of the preference $F_{\text {cpf }}-F_{\text {land }}$. For $\sigma=100$ and $200 \mathrm{~m}$, the preference is positive through the cold pool lifetime, indicating that cold pools are located near small-scale valleys throughout their life. However, the preference for the large-scale length shows that younger cold pools are more likely to be located near large-scale ridges. As they age, they then tend to be located nearer to large-scale valleys. This suggests that cold pools descend from a large-scale ridge through small-scale valleys to a larger-scale valley. As valleys are orographically formed so that water flows efficiently to the lowest altitude, the downward migration of cold pools is not prevented by submesoscale topography.

We also conducted sensitivity tests in these analyses with different parameters of $\Delta t, Q_{l}$, and $R$ and the same analyses individually for each case: $\Delta T=3 \mathrm{~K} \mathrm{~h}^{-1}, Q_{l}=100 \mathrm{~g} \mathrm{~m}^{-2}$, and $R=5 \mathrm{~km}$. As well as the sensitivity tests in the upslope flow composite analysis, these show qualitatively same results as those obtained above.

\section{Concluding remarks}

In this study, the influence of submesoscale topography on precipitation associated with thermally driven local circulations over a mountainous region was investigated using an LES experiment on a 100-m mesh. Submesoscale topography was observed to have a weakening effect on precipitation. Upslope flow, thermally driven by daytime solar heating of the mountain surface, interacts with submesoscale topographic features, leading to detachment of the upslope flow from the land surface and vertical turbulent mixing. This tends to weaken the upslope flow and its mass and moisture transport toward large-scale mountain ridges. These dry processes change the conditions for moist convection around the large-scale ridges: the horizontal size of convection and decrease in equivalent potential temperature. The change in the precondition for large-scale moist convection reduces the amount of precipitation associated with the convergence of upslope flow. These results indicate the importance of considering submesoscale topography and atmospheric variability. 

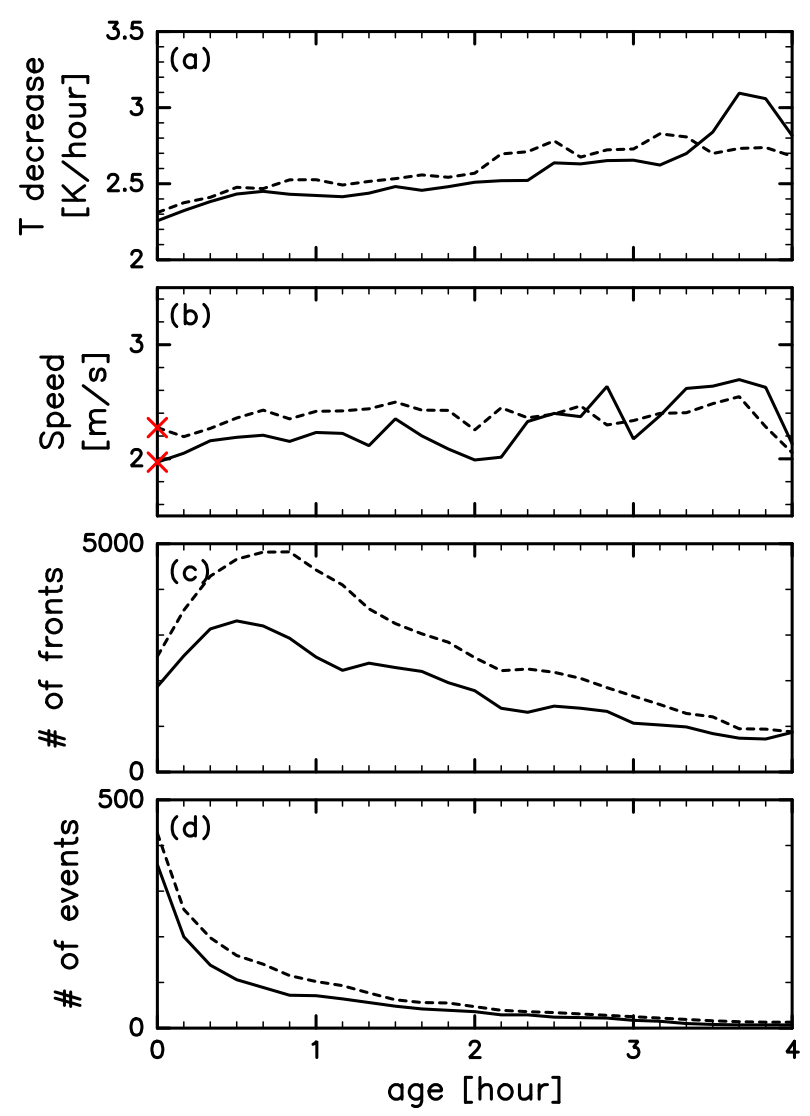

FIG. 20. Temporal evolution of (a) the temperature decrease and (b) velocity of the cold pool and the number of (c) cold pool fronts and (d) cold pool events. The solid and broken lines show the results of TOPO100m and TOPO1km, respectively. The red $\times$ symbol in (b) indicates that the difference is statistically significant at the $99 \%$ confidence level; the temperature differences shown in (a) are not statistically significant. The horizontal axis indicates the age of the cold pool.

The rainfall associated with upslope flow convergence is accompanied by diabatic cooling due to the evaporation of raindrops, generating cold pools around the mountain ridges. These cold pools descend through small-scale valleys, and their downward migration can be another cause of precipitation. The number of cold pools depends on the intensity of the rainfall associated with the upslope flow. The number is greater in TOPO $1 \mathrm{~km}$ than in TOPO100m. The difference in the number of cold pools results in a difference in the amount of precipitation associated with the cold pools: The amount of precipitation is higher in TOPO $1 \mathrm{~km}$ than in TOPO $100 \mathrm{~m}$. In our experiment, this effect enlarged the difference in the total amount of precipitation in the two runs with different topographies. Therefore, cold pools amplify the weakening effect of submesoscale topography on precipitation induced by upslope flow.

Submesoscale topography does not affect the properties of individual cold pools, such as the temperature or speed of migration. The asymmetric characteristic in the effects of small-scale topographic relief between upslope flow driven by
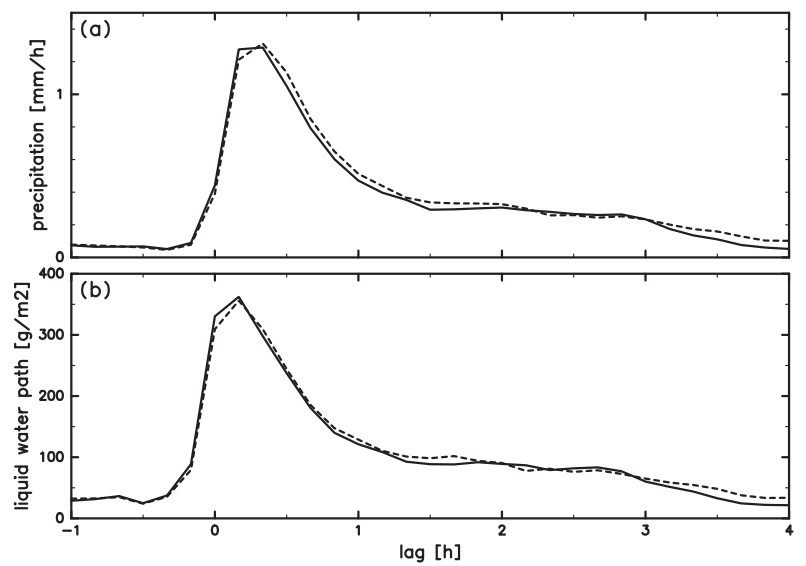

FIG. 21. Composite of temporal change in (a) precipitation rate and (b) liquid water path at the cold pool front points. The solid and broken lines show the results of TOPO100m and TOPO1km, respectively. The horizontal axis is the lag from the time when the front was detected.

surface heating and downslope migration of cold pools is attributed to the orographic nature of realistic terrain: Valleys are formed such that water flows efficiently to the lowest altitude. This result was obtained using realistic topography rather than idealized topography.

Oizumi et al. (2018) and Takemi (2018) both reported that submesoscale topography has an enhancing effect on precipitation. The discrepancy between the results of these studies and the results presented here appears to be due to the background environment. Oizumi et al. (2018) and Takemi (2018) investigated precipitation linked to synoptic-scale systems. Takemi (2018) demonstrated that horizontal convergence near the surface is stronger with finer terrain data. Furthermore, higher mountain and ridge peaks would enhance mechanical forcing such as the enhancement of the trigger processes of moist convection, thereby resulting in increased precipitation and concentration of precipitation areas. Submesoscale topographic features will have an impact on the elevation of mountain peaks and large-scale ridges. At these locations, small-scale features generally have a large amplitude and are in phase with large-scale features (i.e., they peak at approximately the same point). As a result, the elevation, which is the summation of all components, tends to be higher owing to the existence of small-scale features. In fact, Oizumi et al. (2018) and Takemi (2018) pointed to higher mountain peaks for higher-resolution topography data. By contrast, anabatic winds are generally not dominant against background winds under synoptic-scale systems. Background winds tend to have a deeper surface flow than the anabatic flow, on which submesoscale topographic relief has less influence. Therefore, the weakening effect on the surface flow observed herein is not likely to be dominant under large-scale precipitation systems.

This study highlights a new way by which submesoscale topography affects precipitation. Submesoscale topography has a significant impact on large-scale atmospheric phenomena through various processes such as those shown by our 


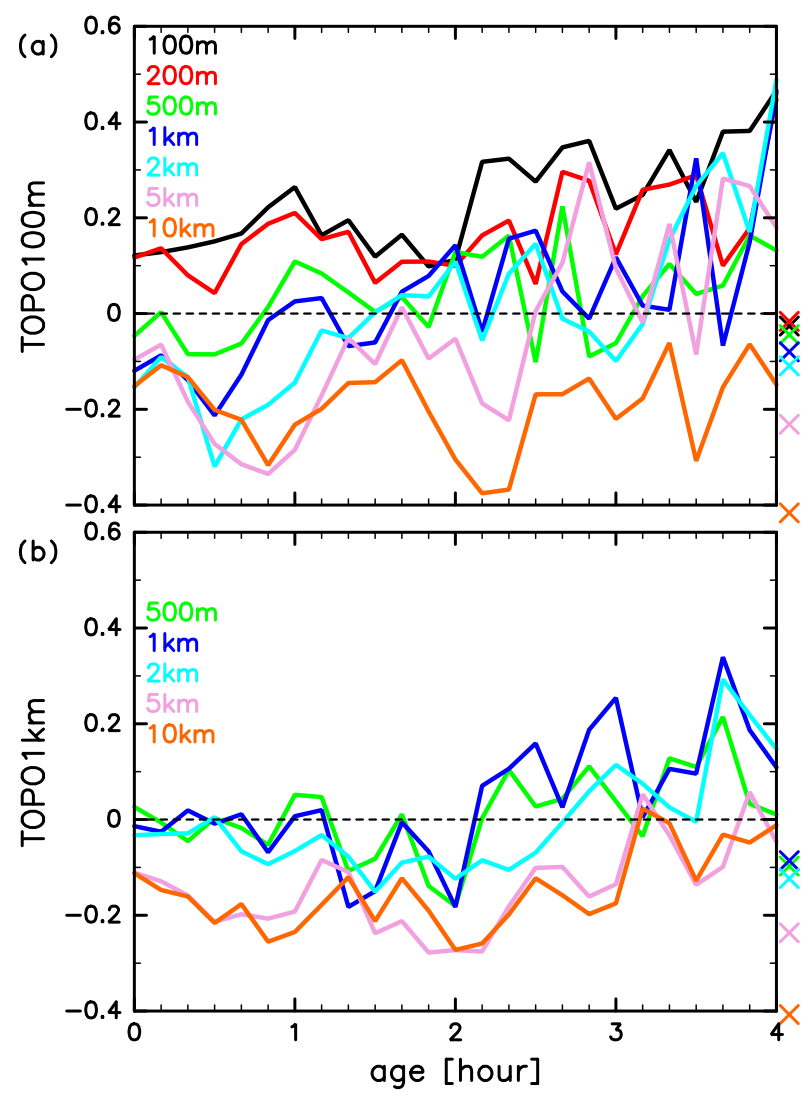

FIG. 22. Temporal evolution of the index $F_{\mathrm{cpf}}-F_{\text {land }}$ of the cold pool front in (a) TOPO100m and (b) TOPO1km. The $\times$ symbols on the right-hand side of the panels represent the index $F_{\text {land }}$. The colors represent the scale length in the ridge/valley detection: $100 \mathrm{~m}$ (black), $200 \mathrm{~m}$ (red), $500 \mathrm{~m}$ (green), $1 \mathrm{~km}$ (blue), $2 \mathrm{~km}$ (cyan), $5 \mathrm{~km}$ (purple), and $10 \mathrm{~km}$ (orange).

current and previous studies depending on the environment. This suggests that developing an understanding of the various effects of submesoscale topography may be a challenge for the future. Mesoscale simulations, wherein the effects of submesoscale topography cannot be explicitly represented, may have nonnegligible errors without considering the effects of submesoscale topography. Understanding these processes better can help improve the accuracy of numerical simulations by introducing a parameterization of the effects of submesoscale topography to mesoscale simulations. For instance, there might be an additional turbulent kinetic energy source in the turbulent scheme that triggers convections in the convection scheme depending on subgrid-scale topography.

Various other interesting topics remain to be explored in order to further understand topographic effects. In this study, we focused on the effect of submesoscale topography on precipitation associated with thermally driven local circulations. It is known that interactions between mechanical and thermal effects exist (Yang et al. 2008; Kirshbaum and Wang 2014; Kirshbaum and Fairman 2015). It is also known that some secondary effects exist. In this study, we investigated the enhancement of the effect by cold pools accompanying precipitation around large-scale ridges as a secondary effect of the topography. Feedback from clouds associated with the topographic thermal effect on convection around largescale ridges may also exist. Wang and Kirshbaum (2015) showed that clouds have negative feedback on topographic thermal effects: Due to convection around ridges, clouds shade solar insolation, which reduces the surface heat flux, weakens upslope flow, and consequently limits convection around the ridge. Precipitation also reduces the surface flux. Wang and Kirshbaum (2015) observed that owing to negative feedback, the moist stability increased only during the early morning. However, in the cases in our study, the moist stability continued to increase in the evening, as shown in Fig. 15. This implies that negative feedback was not significant in our cases. Nevertheless, to understand the effect of submesoscale topography quantitatively, exploration of such interactions and feedbacks is important.

Acknowledgments. The first author extends his thanks to all members of the Climate Research Team at the RIKEN Center for Computational Science, especially Dr. Tomita and Dr. Adachi, for their insightful comments. This work was supported by JSPS KAKENHI (Grants JP18H05055 and JP19H01974), JST AIP (Grant JPMJCR19U2), and by the Foundation for Computational Science (FOCUS) establishing the Supercomputing Center of Excellence. Some of the results were obtained by using the $\mathrm{K}$ computer at the RIKEN Center for Computational Science and the Oakbridge-CX in the Information Technology Center, The University of Tokyo. The diagrams in this paper were drawn with the tools developed by the GFD-Dennou Club (https://www.gfd-dennou.org/ index.html.en).

Data availability statement. The source code of SCALE-RM and simulation configuration files used in this study are available from the Zenodo repository at https://doi.org/10.5281/ zenodo.3674990. JMA Global Analysis and Radar-AMeDAS data are available from the Japan Meteorological Business Support Center (http://www.jmbsc.or.jp/en/index-e.html). JMA AMeDAS surface station data are available from the JMA's website (https://www.data.jma.go.jp/gmd/risk/obsdl/ index.php). The 50-m-mesh digital elevation model is available from the Japan Map Center (https://www.jmc.or.jp/ english/). The MGDSST used as the sea surface temperature dataset is available from the North East Asian RegionalGlobal Ocean Observing System (NEAR-GOOS) Regional Real Time Database (http://ds.data.jma.go.jp/gmd/goos/data/ database.html). The simulation data are stored locally at RIKEN R-CCS.

\section{APPENDIX}

\section{Ridge and Valley Detection}

The ridge (valley) is defined as the points that are the local maxima (minima) in surface elevation in one direction. The detection procedure of Lindeberg (2008) was adopted. 
TOP0 $100 \mathrm{~m}$

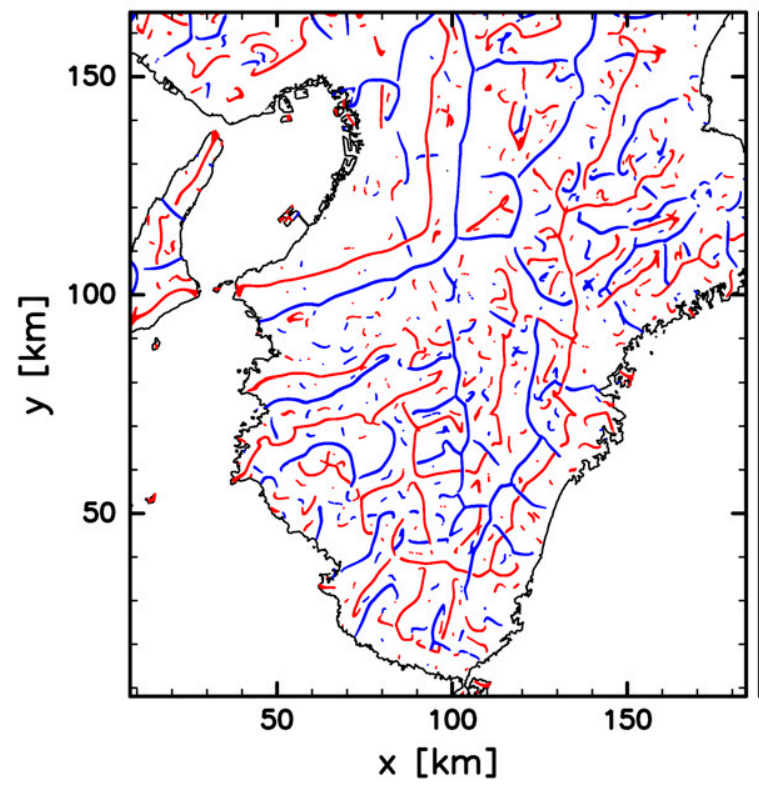

TOP01 km

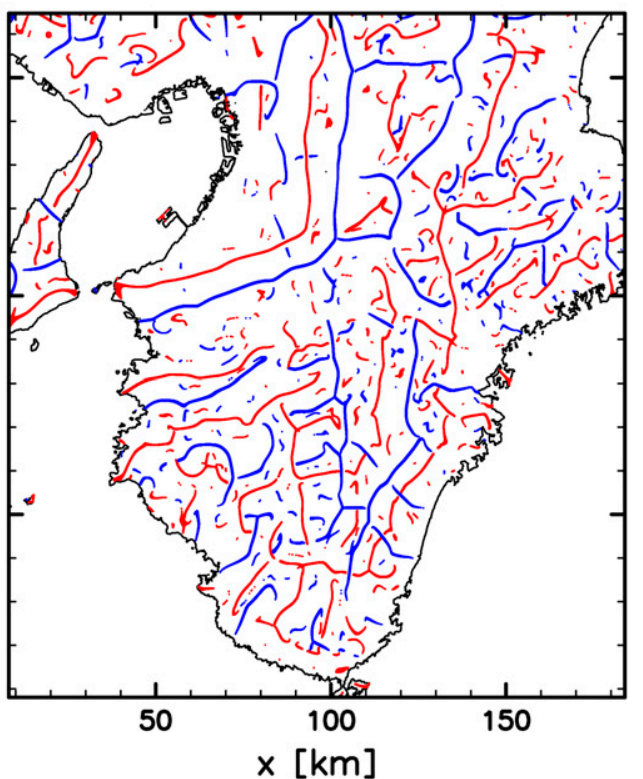

FIG. A1. Ridges (red) and valleys (blue) detected with $\sigma=2 \mathrm{~km}$.

First, the smoothed elevation field $L$, called the scale-space representation, is calculated using a Gaussian filter with a scale length $\sigma$ from the surface elevation $h$ :

$$
L(x, y ; \sigma)=\frac{\int_{\xi^{2}+\eta^{2} \leq(n \sigma)^{2}} h(x-\xi, y-\eta) \exp \left(-\frac{\xi^{2}+\eta^{2}}{2 \sigma^{2}}\right) d \xi d \eta}{\int_{\xi^{2}+\eta^{2} \leq(n \sigma)^{2}} \exp \left(-\frac{\xi^{2}+\eta^{2}}{2 \sigma^{2}}\right) d \xi d \eta},
$$

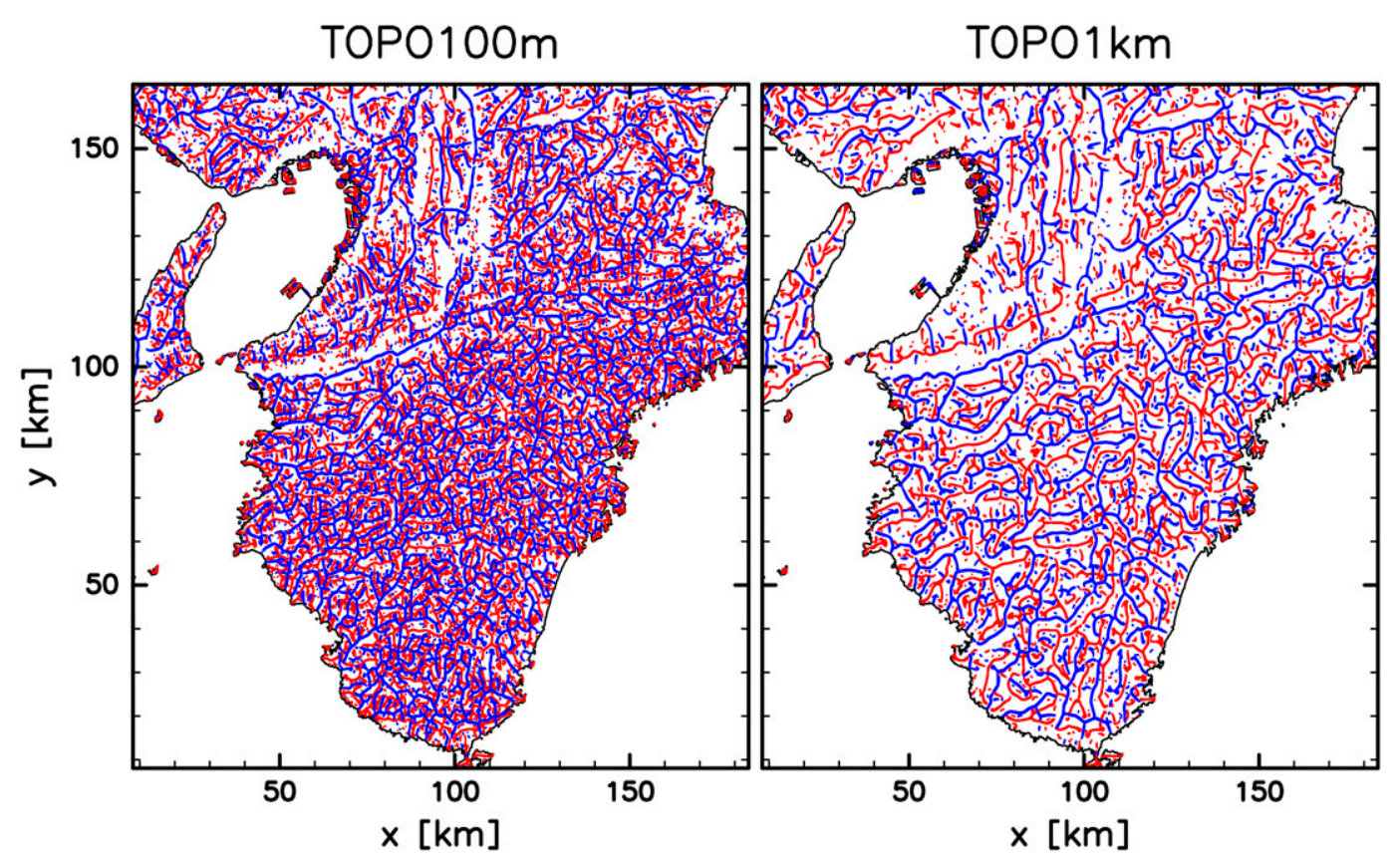

FIG. A2. As in Fig. A1, but $\sigma=500 \mathrm{~m}$. 
where $n$ is a truncation limit introduced in this study and set at $n=4$, and where the value of the exponential function is almost 0 . Next, the eigenvalues $L_{p p}$ and $L_{q q}$, where $L_{p p} \leq L_{q q}$, of the Hessian matrix $\mathbf{H}$ are calculated, where

$$
\mathbf{H}=\left(\begin{array}{ll}
L_{x x} & L_{x y} \\
L_{x y} & L_{y y}
\end{array}\right) .
$$

Here, the subscription represents a differential. A ridge is defined as a point where $L_{p}=0, L_{p p}<0$, and $\left|L_{p p}\right| \geq\left|L_{q q}\right|$, where $L_{p}$ is the first derivative in the direction of the eigenvector corresponding to the eigenvalue $L_{p p}$, and

$$
\begin{aligned}
L_{p} & =\sin \beta L_{x}-\cos \beta L_{y}, \\
\cos \beta & =\sqrt{\frac{1}{2}\left[1+\frac{L_{x x}-L_{y y}}{\sqrt{\left(L_{x x}-L_{y y}\right)^{2}+4 L_{x y}^{2}}}\right]} .
\end{aligned}
$$

Similarly, a valley is defined as a point where $L_{q}=0, L_{q q}>0$, and $\left|L_{q q}\right| \geq\left|L_{p p}\right|$.

For numerical calculations, the condition that $L_{p}$ is the local minimum was used in this study instead of the condition $L_{p}=0$.

Figure A1 shows the ridges and valleys detected with $\sigma=$ $2 \mathrm{~km}$. As components of topography larger than $2 \mathrm{~km}$ are almost identical between TOPO100m and TOPO $1 \mathrm{~km}$, the detected ridges and valleys are very similar between the two runs. A notable difference can be detected with $\sigma=500 \mathrm{~m}$ (Fig. A2). Much smaller-scale ridges and valleys can be seen in TOPO100m.

\section{REFERENCES}

Banta, R. M., 1984: Daytime boundary-layer evolution over mountainous terrain. Part I: Observations of the dry circulations. Mon. Wea. Rev., 112, 340-356, https://doi.org/10.1175/ 1520-0493(1984)112<0340:DBLEOM > 2.0.CO;2.

Beljaars, A. C. M., 1995: The parameterization of surface fluxes in large-scale models under free convection. Quart. J. Roy. Meteor. Soc., 121, 255-270, https://doi.org/10.1002/ qj.49712152203.

Brown, A. R., S. H. Derbyshire, and P. J. Mason, 1994: Large-eddy simulation of stable atmospheric boundary layers with a revised stochastic subgrid model. Quart. J. Roy. Meteor. Soc., 120, 1485-1512, https://doi.org/10.1002/qj.49712052004.

Bryan, G. H., J. C. Wyngaard, and J. M. Fritsch, 2003: Resolution requirements for the simulation of deep moist convection. Mon. Wea. Rev., 131, 2394-2416, https://doi.org/10.1175/15200493(2003)131<2394:RRFTSO > 2.0.CO;2.

Daly, C., M. Halbleib, J. I. Smith, W. P. Gibson, M. K. Doggett, G. H. Taylor, J. Curtis, and P. P. Pasteris, 2008: Physiographically sensitive mapping of climatological temperature and precipitation across the conterminous United States. Int. J. Climatol., 28, 2031-2064, https://doi.org/10.1002/joc.1688.

Egger, J., 1990: Thermally forced flows: Theory. Atmospheric Processes Over Complex Terrain, Meteor. Monogr., Vol. 23, Amer. Meteor. Soc., 43-58, https://doi.org/10.1007/978-1-935704-25-6_3.

Emori, S., 1998: The interaction of cumulus convection with soil moisture distribution: An idealized simulation. J. Geophys. Res., 103, 8873-8884, https://doi.org/10.1029/98JD00426.
Frei, C., and C. C. Schär, 1998: A precipitation climatology of the Alps from high-resolution rain-gauge observations. Int. J. Climatol., 18, 873-900, https://doi.org/10.1002/(SICI)10970088(19980630)18:8<873::AID-JOC255>3.0.CO;2-9.

Hagen, M., J. van Baelen, and E. Richard, 2011: Influence of the wind profile on the initiation of convection in mountainous terrain. Quart. J. Roy. Meteor. Soc., 137, 224-235, https:// doi.org/10.1002/qj.784.

Hoerner, S. F., 1965: Fluid-Dynamic Drag: Practical Information on Aerodynamic Drag and Hydrodynamic Resistance. Hoerner Fluid Dynamics, $455 \mathrm{pp}$.

Houze, R. A., Jr., 2012: Orographic effects on precipitating clouds. Rev. Geophys., 50, RG1001, https://doi.org/10.1029/ 2011RG000365.

Kalthoff, N., and Coauthors, 2011: The dependence of convectionrelated parameters on surface and boundary-layer conditions over complex terrain. Quart. J. Roy. Meteor. Soc., 137, 70-80, https://doi.org/10.1002/qj.686.

Kimura, F., and T. Kuwagata, 1995: Horizontal heat fluxes over complex terrain computed using a simple mixed-layer model and a numerical model. J. Appl. Meteor., 34, 549-558, https:// doi.org/10.1175/1520-0450-34.2.549.

Kirshbaum, D. J., 2011: Cloud-resolving simulations of deep convection over a heated mountain. J. Atmos. Sci., 68, 361-378, https://doi.org/10.1175/2010JAS3642.1.

— fields by mesoscale ascent. Quart. J. Roy. Meteor. Soc., 138, 2136-2150, https://doi.org/10.1002/qj.1954.

—_, and C. Wang, 2014: Boundary layer updrafts driven by airflow over heated terrain. J. Atmos. Sci., 71, 1425-1442, https:// doi.org/10.1175/JAS-D-13-0287.1.

, and J. G. Fairman, 2015: Cloud trails past the Lesser Antilles. Mon. Wea. Rev., 143, 995-1017, https://doi.org/10.1175/MWRD-14-00254.1.

— B. Adler, N. Kalthoff, C. Barthlott, and S. Serafin, 2018: Moist orographic convection: Physical mechanisms and links to surface-exchange processes. Atmosphere, 9, 80, https:// doi.org/10.3390/atmos9030080.

Kuwagata, T., A. Numaguti, and N. Endo, 2001: Diurnal variation of water vapor over the central Tibetan Plateau during summer. J. Meteor. Soc. Japan, 79, 401-418, https://doi.org/ 10.2151/jmsj.79.401.

Lindeberg, T., 2008: Scale-space. Wiley Encyclopedia of Computer Science and Engineering, B. W. Wah, Ed., Vol. IV, John Wiley and Sons, 2495-2504, https://doi.org/10.1002/9780470050118.ecse609.

Lott, F., and M. J. Miller, 1997: A new subgrid-scale orographic drag parameterization: Its formulation and testing. Quart. J. Roy. Meteor. Soc., 123, 101-127, https://doi.org/10.1002/ qj. 49712353704.

Milton, S. F., and C. A. Wilson, 1996: The impact of parameterized subgrid-scale orographic forcing on systematic errors in a global NWP model. Mon. Wea. Rev., 124, 2023-2045, https:// doi.org/10.1175/1520-0493(1996)124<2023:TIOPSS>2.0.CO;2.

Nakanishi, M., and H. Niino, 2009: Development of an improved turbulence closure model for the atmospheric boundary layer. J. Meteor. Soc. Japan, 87, 895-912, https://doi.org/10.2151/ jmsj.87.895.

Nishizawa, S., and Y. Kitamura, 2018: A surface flux scheme based on the Monin-Obukhov similarity for finite volume models. J. Adv. Model. Earth Syst., 10, 3159-3175, https://doi.org/ 10.1029/2018MS001534.

—, H. Yashiro, Y. Sato, Y. Miyamoto, and H. Tomita, 2015: Influence of grid aspect ratio on planetary boundary layer 
turbulence in large-eddy simulations. Geosci. Model Dev., 8 , 3393-3419, https://doi.org/10.5194/gmd-8-3393-2015.

Oizumi, T., K. Saito, J. Ito, T. Kuroda, and L. Duc, 2018: Ultrahigh-resolution numerical weather prediction with a large domain using the $\mathrm{K}$ computer: A case study of the Izu Oshima heavy rainfall event on October 15-16, 2013. J. Meteor. Soc. Japan, 96, 25-54, https://doi.org/10.2151/jmsj.2018-006.

Panosetti, D., S. Böing, L. Schlemmer, and J. Schmidli, 2016: Idealized large-eddy and convection-resolving simulations of moist convection over mountainous terrain. J. Atmos. Sci., 73, 4021-4041, https://doi.org/10.1175/JAS-D-15-0341.1.

Pritchard, P. J., and J. C. Leylegian, 2011: Fox and McDonald's Introduction to Fluid Mechanics. John Wiley and Sons, $875 \mathrm{pp}$.

Roe, G. H., 2005: Orographic precipitation. Annu. Rev. Earth Planet. Sci, 33, 645-671, https://doi.org/10.1146/annurev.earth.33.092203.122541.

Sato, Y., S. Nishizawa, H. Yashiro, Y. Miyamoto, Y. Kajikawa, and H. Tomita, 2015: Impacts of cloud microphysics on trade wind cumulus: Which cloud microphysics processes contribute to the diversity in a large eddy simulation? Prog. Earth Planet. Sci., 2, 23, https://doi.org/10.1186/s40645-0150053-6.

Schmidli, J., 2013: Daytime heat transfer processes over mountainous terrain. J. Atmos. Sci., 70, 4041-4066, https://doi.org/ 10.1175/JAS-D-13-083.1.

Scotti, A., C. Meneveau, and D. K. Lilly, 1993: Generalized Smagorinsky model for anisotropic grids. Phys. Fluids, $\mathbf{5 A}$, 2306-2308, https://doi.org/10.1063/1.858537.

Sekiguchi, M., and T. Nakajima, 2008: A $k$-distribution-based radiation code and its computational optimization for an atmospheric general circulation model. J. Quant. Spectrosc. Radiat. Transfer, 109, 2779-2793, https://doi.org/10.1016/ j.jqsrt.2008.07.013.

Serafin, S., and D. Zardi, 2010: Daytime heat transfer processes related to slope flows and turbulent convection in an idealized mountain valley. J. Atmos. Sci., 67, 3739-3756, https://doi.org/ 10.1175/2010JAS3428.1.

Smith, R. B., 1979: The influence of mountains on the atmosphere. Advances in Geophysics, Vol. 21, Academic Press, 87-230, https://doi.org/10.1016/S0065-2687(08)60262-9.
— 1989: Hydrostatic airflow over mountains. Advances in Geophysics, Vol. 31, Elsevier, 1-41, https://doi.org/10.1016/ S0065-2687(08)60052-7.

_ I. Barstad, and L. Bonneau, 2005: Orographic precipitation and Oregon's climate transition. J. Atmos. Sci., 62, 177-191, https://doi.org/10.1175/JAS-3376.1.

— , P. Schafer, D. J. Kirshbaum, and E. Regina, 2009: Orographic precipitation in the tropics: Experiments in Dominica. J. Atmos. Sci., 66, 1698-1716, https://doi.org/10.1175/2008JAS2920.1.

Takemi, T., 2018: Importance of terrain representation in simulating a stationary convective system for the July 2017 northern Kyushu heavy rainfall case. SOLA, 14, 153-158, https://doi.org/10.2151/ sola.2018-027.

Tomita, H., 2008: New microphysical schemes with five and six categories by diagnostic generation of cloud ice. J. Meteor. Soc. Japan, 86A, 121-142, https://doi.org/10.2151/jmsj.86A.121.

Turner, J. S., 1962: The 'starting plume' in neutral surroundings. J. Fluid Mech., 13, 356-368, https://doi.org/10.1017/ S0022112062000762.

Wagner, J. S., A. Gohm, and M. W. Rotach, 2014: The impact of horizontal model grid resolution on the boundary layer structure over an idealized valley. Mon. Wea. Rev., 142, 34463465, https://doi.org/10.1175/MWR-D-14-00002.1.

,-- , and,- 2015 : The impact of valley geometry on daytime thermally driven flows and vertical transport processes. Quart. J. Roy. Meteor. Soc., 141, 1780-1794, https:// doi.org/10.1002/qj.2481.

Wang, C., and D. J. Kirshbaum, 2015: Thermally forced convection over a mountainous tropical island. J. Atmos. Sci., 72, 24842506, https://doi.org/10.1175/JAS-D-14-0325.1.

Wilson, D. K., 2001: An alternative function for the wind and temperature gradients in unstable surface layers. Bound.-Layer Meteor., 99, 151-158, https://doi.org/10.1023/A:1018718707419.

Yang, Y., S. Xie, and J. Hafner, 2008: The thermal wake of Kauai Island: Satellite observations and numerical simulations. J. Climate, 21, 4568-4586, https://doi.org/10.1175/2008JCLI1895.1.

Yoshida, R., S. Nishizawa, H. Yashiro, S. A. Adachi, Y. Sato, T. Yamaura, and H. Tomita, 2017: CONeP: A cost-effective online nesting procedure for regional atmospheric models. Parallel Comput., 65, 21-31, https://doi.org/10.1016/j.parco.2017.04.004. 